Thorax (1955), 10, 269.

\title{
THE PATHOLOGY OF SEVERE DIGESTION OESOPHAGITIS
}

\author{
BY \\ P. M. PETERS \\ From the Central Histological Laboratory, Archway Wing, Whittington Hospital, and the Department of \\ Pathology, the Royal Northern Hospital, London
}

(RECEIVED FOR PUBLICATION AUGUST 2, 1955)

That one part of the body should be at permanent hazard from the secretions of another seems an oddity of nature; yet the oesophagus has to protect itself from being digested alive by the powerful enzymes of the stomach. That it might fail to do so was early suggested by Quincke (1879), who described three cases of "ulcus oesophagi ex digestione" (Fig. 1). Several isolated oesophageal ulcers were recorded before this, but their exact nature remains uncertain; thus, of two cases in 1784 (Simmons ; Garth- shore) the former may have been peptic ulceration, but the latter (necropsy by John Hunter) was possibly an ulcerated and perforated carcinoma.

Although digestion, peptic, or reflux oesophagitis is now known to be common, its very existence was not widely appreciated until recently and its effects are often underestimated. The present paper consists of an outline of the main developments in the literature and a report of investigations made.
FIG. 1.-The illustrations from Quincke's paper published in 1879.

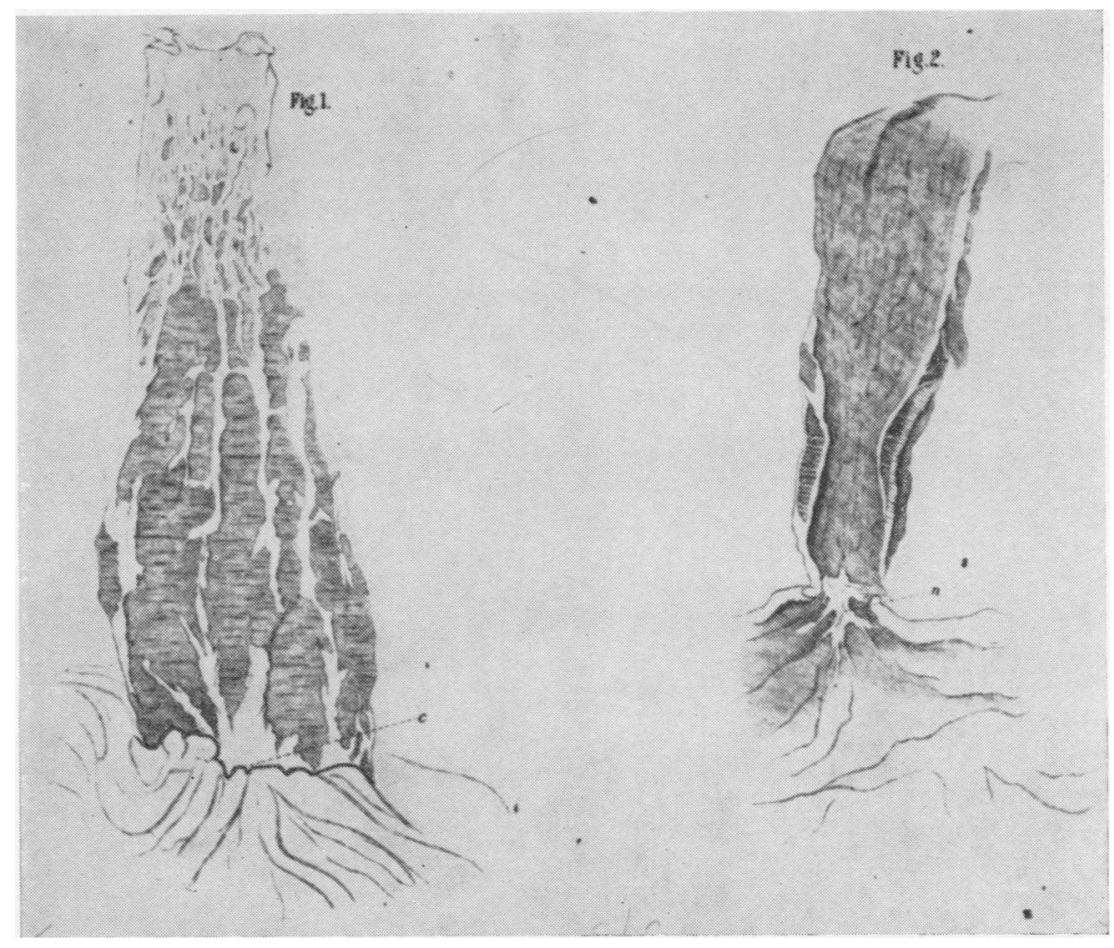




\section{GASTRIC SECRETION AS A DIRECT CAUSE OF OESOPHAGITIS}

Peptic digestion of living tissue is a well-known phenomenon, e.g., round fistulae, and was demonstrated by Claude Bernard (1859; see Price and Lee, 1946). Price and Lee themselves showed that only autogenous gastric epithelium is immune from peptic digestion in dogs (1946) and that digestion of other tissues is accelerated by hyperchlorhydria (1947).

Strong pathological and clinical evidence of ante-mortem digestion of the oesophagus has come from many sources after Quincke, e.g., Tileston (1906), Pringle and Teacher (1919), Hurst and Stewart (1929), Chevalier Jackson (1929), Bartels (1935), Lyall (1937), Johnstone (1943), Allison, Johnstone, and Royce (1943), Allison (1946, 1948, 1951, and 1953), Barrett and Franklin (1949), Lawler and McCreath (1951), Barrett (1950, 1954), and Belsey (1953). Some authors, however, notably Chevalier Jackson (1929), Allison (1951), and Harman (1952), considered that some additional factor or factors might also be necessary. Barrett and Franklin gave a vivid description of normal-looking mucosa becoming raw and bleeding when dilatation of an oesophageal stricture permitted renewed regurgitation.

Selye (1938) produced lower oesophagitis in rats by tying the pylorus; control rats, with the cardia also tied, were immune. Arroyave, Clatworthy, and Wangensteen (1950) and Ripley, Leary, Grindlay, Seybold, and Code (1950) caused oesophagitis in dogs by implanting gastric mucosa in the gullet; both groups found that digestion was accelerated in histaminized (hyperchlorhydric) dogs.

Barrett (1954) noted that oesophagitis could also be caused by regurgitated duodenal contents.

\section{PREDISPOSING CONDITIONS}

\section{GeNeraL}

As would be expected, persistent vomiting has frequently been found in association with oesophagitis (Tileston, 1906; Stewart and Hartfall, 1929 ; Bartels, 1935 ; Butt and Vinson, 1936a and b ; Hurst, 1937 ; Terracol, 1938 ; Johnstone, 1943 ; Gerlings, 1949 ; Lodge, 1955a ; Franklin, 1955). Butt and Vinson, quoting Vinson, 1923, described nine cases of oesophageal stricture following vomiting of pregnancy and Hurst a case of oesophagitis from persistent sea-sickness.

Association has also often been noted with chronic gastric or duodenal ulcers (e.g., by Tileston, 1906 ; Stewart and Hartfall, 1929 ; Lyall, 1937 ; Johnstone, 1943 ; Allison, 1946 ; and Gerl- ings, 1949) and with gastric hyperacidity (Pringle and Teacher, 1919; Abel, 1929 ; Lyall, 1935 ;을

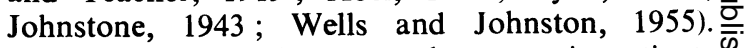
Oesophagitis can also occur, however, in patients $\frac{\bar{c}}{\sigma}$ with achlorhydria (Barrett, 1954), and according $\mathscr{\complement}$ to Aylwin (see Allison, 1953) the pepsin activity of the gastric juice is more important than the $\vec{\circ}$ acid content.

A factor of wide significance is increase of $\vec{\omega}$ intra-abdominal pressure which favours both gastric reflux and pulsion hiatal hernia (Tileston, $\vec{x}$ 1906 ; Schatzki, 1932 ; Hurst, 1934 ; Johnstone, $\vec{\circ}$ 1943 ; Barrett, 1954 ; Wells and Johnston, 1955). Rennie, Land, and Scott Park (1949) reported N oesophagitis with shortening in the late stages of pregnancy without vomiting.

Buccal and nasal sepsis, chronic alcoholism, and cholecystitis have also been suggested as predispos- $\Phi$ ing causes. Many have noted that the disease is $\Phi$ more likely in debilitated, toxic or shocked sub- $\frac{3}{0}$ jects, where the important factor of the supine $\frac{\mathbb{D}}{-}$ position is also likely to operate (Lodge, 1955b). $\vec{c}$

\section{LOCAL}

The most important is hiatal hernia with shortening of the oesophagus (see below). Others are gastric ulcer at the cardia (Tileston, 1906) and surgical operations in the area, especially mediastinal oesophago-gastrostomy (Maingot, $1944 ; \mathbb{Q}$ Allison, 1946 ; Barrett and Franklin, 1949).

\section{INCIDENCE AND MORBID ANATOMY}

The disease in all stages was considered rareo until fairly recently. There were many reasons for this, for instance, varied nomenclature and uncorrelated methods of recording; particularly $\underset{\times}{\otimes}$ important, however, was failure to recognize the basic pathology and morbid anatomy and thus to connect the various stages. For example, it 0 was not generally supposed that a few ill-defined erosions with a little altered blood-staining at the 윽 lower end of the tube might be aetiologically $D$ related to dense fibrous stricture there, or that oesophagomalacia might be part of the same N disease which can give patchy or general leukoplakia. Consequently integration as a pathological $\tilde{O}$ entity has been very slow and correlation with $\mathbb{N}^{\circ}$ clinical findings inadequate (see also Allison ando Johnstone, 1953). That the oesophagus is cut justo above the diaphragm in most necropsy techniques is probably an important factor.

Slight acute lesions must often be dismissed as 0 post-mortem change. After systematic investigation Butt and Vinson (1936b) gave $7.02 \%$ (over $\stackrel{\mathbb{Q}}{\overparen{Q}}$ $90 \%$ acute and subacute) for oesophagitis in con- $\stackrel{\mathbb{Q}}{\mathbb{Q}}$ secutive necropsies; Lodge (1955b) found micro- 
scopic evidence of acute oesophagitis in $31 \%$ of 500 unselected hospital patients and in $3 \%$ of 100 "sudden death" cases. The morbid anatomy has been detailed by, among others, Pringle, Stewart, and Teacher (1921), Bartels (1935), Lyall (1935), Terracol (1938), and Lodge (1955a).

That chronic lesions were comparatively common was found by Chevalier Jackson (1929) and Friedenwald, Feldman, and Zinn (1929). By 1951 (Festival Oration) Allison had personally seen 294 cases, 70 with cicatricial stenosis: by 1953 (Allison and Johnstone) 115 cases of stenosis of this type had been seen. It was Allison (1946, with pathological report by Stewart; 1948) who contested the persistent earlier view that the morbid anatomy was similar to that of chronic gastric and duodenal ulcers. Barrett (1950) divided peptic ulcer of the oesophagus into (a) the common type caused by regurgitated gastric juice, characterized by shallow ulcers with marginal leukoplakia and spreading fibrosis, and (b) the rare deep chronic gastric ulcer in a congenital partial thoracic stomach. Three of Barrett's cases are included in the present series.

\section{THE SHORT OESOPHAGUS AND HIATAL} HERNIA

If the oesophagus is too short, part of the stomach must lie in the posterior mediastinum; therefore shortness of the oesophagus is an integral part of one form of hiatal hernia. Whether the shortness is congenital or acquired has been disputed. The congenital origin was supported by Findlay and Kelly (1931), Dunhill (1935), Briggs, Dick, and Hurst (1939), and Dick and Hurst (1942). Findlay and Kelly proposed the term "partial thoracic stomach" as the stomach had never been a wholly abdominal organ (see also Hume, 1932). Later, however, Kelly (1936) thought that some cases were secondary to oesophagitis with ascending fibrosis. Johnstone (1941, 1943), Allison and others (1943), and Allison $(1948,1951)$ concluded that shortness was in fact nearly always acquired as the result of oesophagitis, though conceding that the congenital case did occur rarely. The two conditions were further detailed by Allison and Johnstone (1953) and Barrett (1954); in these papers differing views of the morphogenesis and appropriate nomenclature of the congenital abnormalities were discussed.

Shortening may be directly due to spasm as well as fibrosis; when abolished by anaesthesia or death the tube lengthens and the stomach returns to the abdomen (Kelly, 1936 ; Harrington, 1940 ; Smithers, 1945 ; Rennie and others, 1949).
Primary diaphragmatic defects associated with oesophagitis and shortening may be acquired, e.g., atrophy or hypotonus, or congenital (malformation). In either case the hiatus is large and the pinchcock-elastic ligament mechanism is weak, encouraging reflux and sliding hernia (Anders and Bahrmann, 1932 ; Harrington, 1940 ; Allison, 1948). Barrett (1954) considered the anatomy of the left gastric artery, rather than the integrity of the hiatus, to be the decisive factor preventing hiatal hernia in the normal subject. The effect of posture was stressed by Hurst (1934) and Allison (1951), who showed radiologically the flooding of the gullet when a patient with a weak hiatus bent down. Schatzki (1932) found hiatal hernia in half of 30 unselected old people radiographed lying down; this was increased to $73 \%$ when the intra-abdominal pressure was artificially raised. Minor degrees of partial thoracic stomach are also common in childhood (Carré, Astley, and Smellie, 1952).

\section{SIGNIFICANCE OF GASTRIC MUCOSA IN THE ALIMENTARY TRACT ABOVE THE DIAPHRAGM}

This occurs when the squamous oesophagus is short (see above) or when there are patches of ectopic gastric mucosa in the gullet. The latter has long been recognized (first by Schmidt in 1805 ; see Barrett, 1950), although accounts of the incidence and form have varied. Taylor (1927) found six examples of islets containing chief and oxyntic cells in 900 necropsies, all at the upper end. In Stewart and Hartfall's (1929) case of chronic oesophageal ulcer there were two large post-cricoid gastric patches ; similar patches were present in one of Barrett's cases (1950). Rector and Connerley (1941) found aberrant mucosa, mainly gastric but rarely ciliated, in $11.8 \%$ of 1,000 consecutive oesophaguses from infants and children.

Schridde (1904, see Barrett, 1950) reported gastric mucosa in the post-cricoid area in nearly $70 \%$ of specimens. This high figure suggests that the "cardiac" glands (above the muscularis mucosae), which are very common or normal at the two extremities of the tube, were interpreted as ectopic mucosa; their squamous covering is readily lost post mortem, giving the microscopic appearance of a gastric lining. Another important artefact is that transverse sections through the interdigitated epithelia at the cardia may give the microscopic appearance of an ectopic patch (Diag. 1). True ectopic islets seem to be rare in the lower third; thus in Rector and Connerley's 
series (1941) only $8 \%$ of the observed heterotopes were there and none of these had oxyntic cells. Only a patch wholly surrounded by squamous epithelium should be called ectopic gastric mucosa (Barrett, 1950) and to this the present writer would add that islets without oxyntic cells should be accepted with reserve ; Barrett also noted that chronic gastric ulcer has not so far been shown to have arisen in such a patch. (The case of Kaplan and Zwaifler, 1942, is equivocal.) In this general connexion the present writer recently examined biopsy material from the upper end of the oesophagus which contained adenocarcinoma and gastric epithelium with oxyntic cells. Later, pleural fluid from the same case contained carcinoma cells arranged in tubules.

Clearly the interpretation of "gastric" epithelium removed from the oesophagus may not be simple and involves the differentiation of acquired and congenital thoracic stomach, anomalous gastric linings, ectopic gastric islets, and normal oesophageal cardiac glands.

\section{PRESENT INVESTIGATIONS}

\section{MATERIAL}

This was almost entirely from the collection of the Central Histological Laboratory, Archway Wing, Whittington Hospital, and was derived from 20,000 necropsies. It consisted of histological sections and paraffin blocks from all cases and many gross specimens. During the two years of the investigation (1950 and 1951) specimens of oesophagitis were specially collected, the routine necropsy technique often being modified so that oesophagus, stomach, and diaphragm were removed in one; this was useful in relating lesions anatomically to the insertion of the hiatal elastic ligament.

\section{METHOD}

The histological reports and the cause of death in all cases indexed as ulceration or inflammation of the oesophagus were traced; cases of oesophagitis not due to peptic digestion were then eliminated. Slides of the remainder were examined, fresh sections being cut if necessary, and all slight or doubtful lesions and some with complicating elements, e.g., deep thrush infection, were then excluded.

After this double selection 116 cases remained. The essential facts concerning each patient were then extracted and assembled from the clinical and pathological records (see Peters, 1952). Each case had had a complete necropsy and thorough histological examination and no case was included which was based on a clinical diagnosis not supported by the anatomical facts.

\section{ANalysis AND Discussion}

Aetiology.-Payling Wright (1950) said that predisposing or contributory causes are "the many circumstances which have played their part in bringing the patient under the influence of the initiating causal agent," and in a later passage "... it is the contributory causes which chiefly decide how wide shall be its incidence. . . ." The initiating or direct cause of this form of oesophagitis is ante-mortem digestion by regurgitated gastric secretion and this discussion mainly concerns the predisposing causes. The present cases, already classified as an acute-chronic pathological series, were then allotted to one or more of five groups, according to the predisposing factors found.

Group A.-Failure of cardiac closure mechanisms from extrinsic factors

(i) Persistent vomiting

(ii) Increased intra-abdominal pressure

Group B.-Failure of closure mechanisms from intrinsic factors

(i) Hiatal hernia

(ii) Local congenital malformations

(iii) High lesser curve and cardiac gastric lesions

(iv) Direct neoplastic or inflammatory infiltration of crural tunnel

Group C.-Cases with gastric or duodenal ulcers (presumptive evidence of past or present hyperchlorhydria)

Group D.-Cases with multiple predisposing factors

Group E.-Cases with no recognized predisposing factor

In one case no clinical notes were available $\underset{0}{0}$ and in two of the congenital cases evidence of "gastric" ulcers only was available These three 8 were not included for group percentages, the total $₹$ being thereby reduced from 116 to 113 .

Predisposing factors were found in 105 cases (92.9\%). In eight cases $(7.1 \%)$ no factors were found (Group E), but some allowance may be made for scanty or incomplete records. These figures are held to confirm the original selection of material.

Extrinsic factors were found in $66.3 \%$ (Group A) ; intrinsic in $39.8 \%$ (Group B). Gastric or duodenal ulcers were present in $29.2 \%$ (Group C) and multiple factors in $42.5 \%$ (Group D).

Detailed analysis is given in Table I.
In the tables a single case (of oesophagitis) may appear in different groups or more than once in the same group, or both; hence numbers and $\mathbb{Q}$ percentages shown sometimes exceed figures for group series (Tables II and IV). 
Table I compares the incidence of predisposing factors in Groups A-E in the whole and subdivided series.

TABLE I

PREDISPOSING FACTORS

\begin{tabular}{|c|c|c|c|c|c|c|}
\hline & \multicolumn{2}{|c|}{$\begin{array}{c}\text { Whole } \\
\text { Series } \\
\text { (113 Cases) }\end{array}$} & \multicolumn{2}{|c|}{$\begin{array}{l}\text { Acute and } \\
\text { Subacute } \\
\text { (34 Cases) }\end{array}$} & \multicolumn{2}{|c|}{$\begin{array}{l}\text { Active Chronic } \\
\text { and Chronic } \\
\text { (79 Cases) }\end{array}$} \\
\hline & $\begin{array}{l}\text { No. } \\
\text { of } \\
\text { Cases }\end{array}$ & $\begin{array}{c}\text { Pe:- } \\
\text { centage }\end{array}$ & $\begin{array}{l}\text { No. } \\
\text { of } \\
\text { Cases }\end{array}$ & $\begin{array}{l}\text { Per- } \\
\text { centage } \\
\text { of Sub- } \\
\text { division }\end{array}$ & $\begin{array}{c}\text { No. } \\
\text { of } \\
\text { Cases }\end{array}$ & $\begin{array}{l}\text { Per- } \\
\text { centage } \\
\text { of Sub- } \\
\text { division }\end{array}$ \\
\hline $\begin{array}{l}\text { Group A (extrin- } \\
\text { sic factors) } . \\
\text { Group B (intrin- }\end{array}$ & 75 & $66 \cdot 3$ & 26 & $76 \cdot 5$ & 49 & $62 \cdot 0$ \\
\hline $\begin{array}{l}\text { sic factors) } . . \\
\text { Group C (+ gas- }\end{array}$ & 45 & $39 \cdot 8$ & 11 & $32 \cdot 3$ & 34 & 43.0 \\
\hline $\begin{array}{l}\text { tric or duodenal } \\
\text { ulcers) }\end{array}$ & 33 & $29 \cdot 2$ & 11 & $32 \cdot 3$ & 22 & $27 \cdot 8$ \\
\hline $\begin{array}{c}\text { Group D (mul- } \\
\text { tiple factors).. } \\
\text { Group E (no fac- }\end{array}$ & 48 & $42 \cdot 5$ & 17 & 50.0 & 31 & $39 \cdot 2$ \\
\hline tors found) & 8 & $7 \cdot 1$ & 1 & 2.9 & 7 & $8 \cdot 8$ \\
\hline
\end{tabular}

There is fair comparability in group incidence between the whole and subdivided series; this is important because the range of pathological appearances is wide and the common identity of the disease in acute and chronic cases may sometimes be doubted. The slightly heavier proportion of intrinsic factors (Group B) on the chronic side, with associated reductions in Groups $A$ and $\mathrm{C}$, is due to the congenital cases in which secondary oesophagitis is bound to be chronic, except in the newborn.

Tables II-IV give the disease analysis in Groups A, B, and C.

Conditions in subgroup (1) obviously predispose to digestion oesophagitis, as gastric juice is

TABLE IJ

GROUP A $(66 \cdot 3 \%$ OF TOTAL)

\begin{tabular}{c|c|c}
\hline & $\begin{array}{c}\text { No. of } \\
\text { Cases }\end{array}$ & $\begin{array}{c}\text { Percentage } \\
\text { of Total }\end{array}$ \\
\hline (1) Mainly due to persistent vomiting and & & \\
nausea: & & \\
Dilatation of stomach and paralytic \\
ileus . . .
\end{tabular}

repeatedly in the gullet, not only during every vomit but often as a residue held above the pinchcock or running freely up the tube. Prolonged nausea is perhaps associated with gastric anti-peristalis and consequent regurgitation. Raised abdominal pressure (subgroup 2) operated in two ways: by favouring pulsion hiatal hernia and by forcing stomach contents into the oesophagus especially in certain postures.

The subgroups are qualified by the word " mainly" because both factors might be present in the same case; such were classified according to the most important, assessed by combining the clinical evolution with the necropsy findings.

It is noteworthy that 38 cases or a third of the total had either dilatation of the stomach, paralytic ileus, pyloric or duodenal obstruction, or small intestine obstruction.

TABLE III

GROUP B $(39.8 \%$ OF TOTAL)

\begin{tabular}{|c|c|c|}
\hline & $\begin{array}{l}\text { No. of } \\
\text { Cases }\end{array}$ & $\begin{array}{l}\text { Percentage } \\
\text { of Total }\end{array}$ \\
\hline 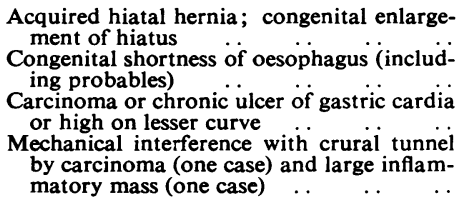 & $\begin{array}{l}23 \\
11\end{array}$ & 9.7 \\
\hline
\end{tabular}

Groups A and B are not completely separable, as in the case of hiatal hernia associated with raised abdominal pressure (see above). Such cases were classified in both groups, but some small herniae may have been missed at necropsy or have been self-reducing after death, and in this way Group $B$ may be an underestimate, also because the effect of posture in relation to sliding hiatal hernia cannot be assessed in a primarily pathologically controlled series. As against these, however, nine cases of fixed hiatal hernia were included in the group because, whatever the original cause, the final result ensured permanent hiatal incompetence. This is illustrated in the following general scheme.

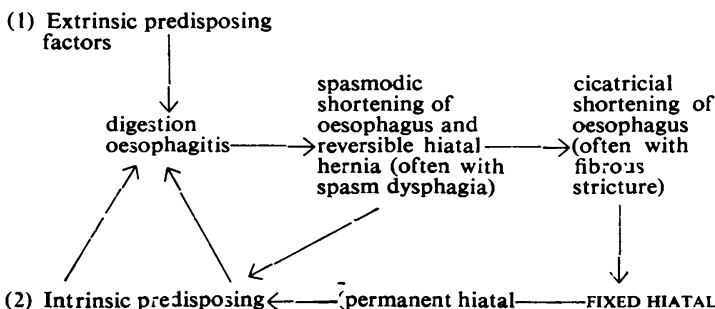

(2) Intrinsic predisposing $\leftarrow$ incompetence) 
The initiating point of the sequence may be clear in the history or at necropsy; it may equally be an event inaccessible in the patient's past.

Fixed hiatal hernia is occasionally produced by traction, for example, by oesophageal cancer, or by massive displacement of the mediastinum with lengthening, not shortening, of the tube, e.g., gross unilateral fibroid phthisis in one case of this series. A technical point in the pathology of hiatal hernia is that, if a small knuckle of stomach is easily drawn into the chest in the routine necropsy " pluck," the condition is likely to have been present at least intermittently during life. The aorta takes most of the pull as the thoracic viscera are drawn out and back over the liver, and, normally, if the stomach is drawn up at all the diaphragm is drawn up likewise.

Congenital anomalies in Group B involved the oesophagus, stomach, and diaphragm; the pathology of these will be discussed in a separate communication.

TABLE IV

GROUP C $(29 \cdot 2 \%$ OF TOTAL)

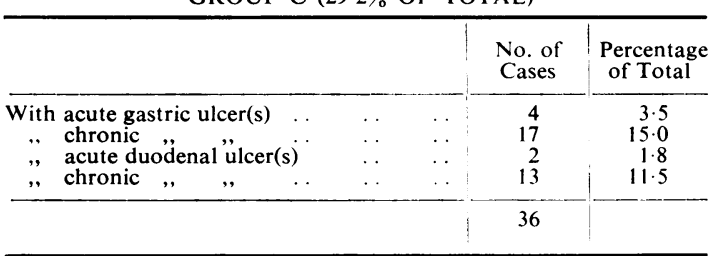

As this group includes nearly a third of the series [cf., Tileston's figure of $33 \%$, Gerling's of $44 \%$, loc. cit., and Lyall's of $50 \%$ (1937) ] oesophagitis is clearly more likely if gastric reflux is hyperacid. Normal or hypochlorhydric juice may need much longer application to be injurious.

No detailed analysis of Group D is given, as no significant correlation of multiple factors emerged. By definition the group consists of cases classified in A, B, and C. Multiple factors were either of different groups or different factors in the same group. Also a single lesion may predispose in more than one way, for example, pyloric obstruction due to chronic ulcer (vomiting plus presumed hyperchlorhydria). An extreme example of multiple factors in this series was a case of severe acute oesophagitis in a patient who had general peritonitis, with greatly dilated stomach and small intestine, reducible hiatal hernia with a wide hiatus, and a large chronic duodenal ulcer; she was also hugely obese.

General INCIDENCE.-Allowing for two cases from a different series of necropsies and two congenital cases with recorded "gastric" type ulcers only, the overall incidence in this series (all stages) is $0.56 \%$ of all necropsies (112 cases ; 19,931 necropsies), of which $0.18 \%$ were acute and $0.38 \%$ chronic.

Various factors bear on the validity of these figures. Specimens were actively collected in 1950 and 1951, and in Table $\mathrm{V}$ the figures for these years are compared with those of the preceding 19 years ; clearly the focusing of attention affected both the total collected and the ratio of acute to chronic. The 1950-1 figures are therefore taken as the most representative : figures from other published series are included for comparison. The general incidence in this series is thus of the order of 1 in 100 necropsies $(0.92 \%)$, acute and chronic lesions occurring in roughly similar proportions $(0.41 \%$ and $0.51 \%$ respectively). Mild lesions in all stages (not included) are undoubtedly much more common and would largely account for the variation in the published series (see Lodge, 1955).

TABLE $\mathrm{V}$

GENERAL INCIDENCE IN 1950-5I COMPARED WITH EARLIER SERIES

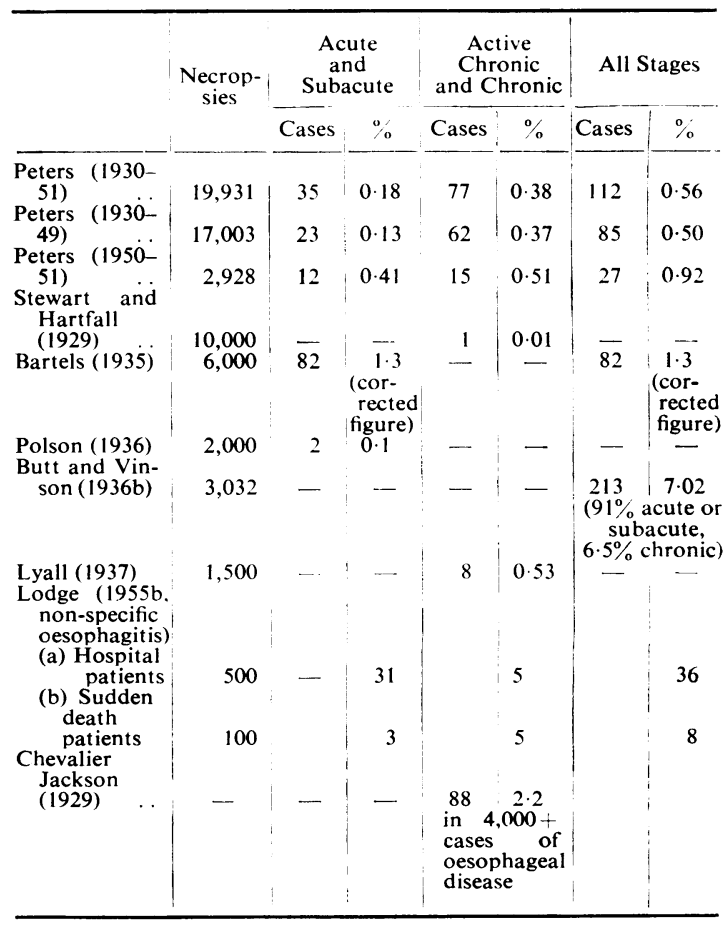

Age InCIDENCE.- No age is exempt. The range in this series included infants of less than 1 year and octogenarians. No significant age difference between acquired and congenital groups was found 


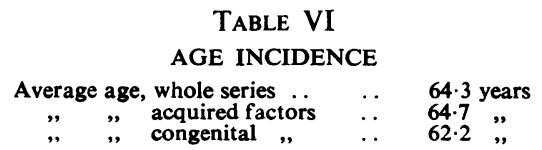

SEX INCIDENCE.-No substantial difference was found, but there was slight overall male preponderance $(1.3: 1)$, possibly related to the greater incidence of duodenal ulcers in the male. It seems likely therefore that pregnancy only rarely causes serious oesophagitis. The male preponderance was in both stages, but more marked in the acute (2.8: 1 acute; $1.08: 1$ chronic). The numbers in the congenital group were too small for significant separate sex comparison.

TABLE VII

SEX INCIDENCE

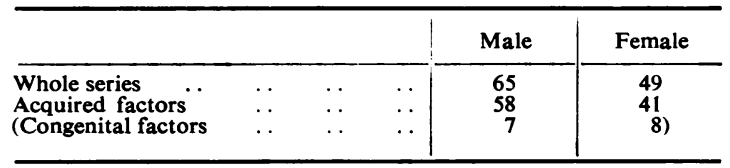

\section{Morbid ANATOMY}

General Features (All Stages).-The lesion is sharply limited below by gastric mucosa, unless the terminal oesophagus is partly protected by a strong diaphragmatic " pinchcock" (Peters, 1955).

Each layer of the wall tends to protect the one external to it, so that destruction occurs in steps with a shallow terraced effect on section.

The changes, whatever their extent, are most severe distally, as the damaging agent comes up from below.

Microscopic changes are wider than appear to the naked eye ; acute on chronic inflammation is common, implying repeated attacks.

Inhalation bronchopneumonia and perforation into mediastinum, pleura, or pericardium are risks in all stages. Perforation at or below the attachment of the hiatal elastic ligament leads to upper peritonitis with or without pleurisy (Peters, 1955).

If surface layers, including submucosal glands, are destroyed and the hiatal ligament not included in the section the oesophagus and the stomach are similar microscopically (see also Barrett, 1954). Hence oesophageal ulceration, acute or chronic, extending to gastric mucosa may look like ulceration through gastric mucosa, especially in crosssection through the epithelial interdigitations at the cardia (Diag. 1). This is an important point in pathological diagnosis.

As in all inflammation there is no abrupt division between stages either macroscopically or microscopically.

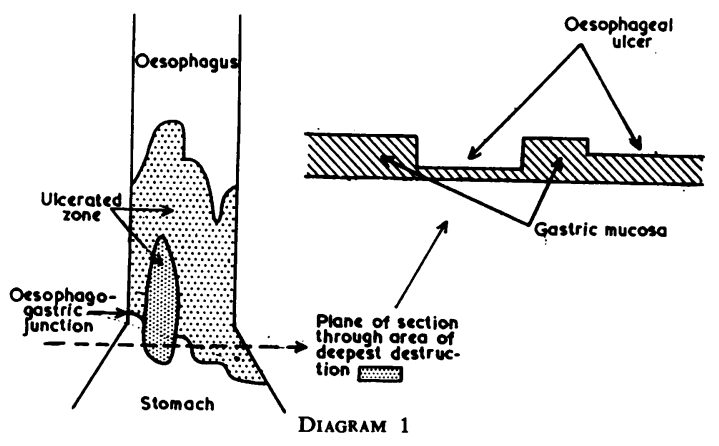

Macroscopic Appearances.-For convenience these are divided into acute and chronic.

Acute.-The appearances vary widely, chiefly by different combinations of severity and extent. Just the lower end or any proportion of the whole tube may be involved. The mucosa is invariably shed to some extent, but in mild cases this may be difficult to define, especially if there is diffuse haemoglobin-staining from lysed blood which is easily taken for post-mortem staining. Discrete shallow ulcers with brown or blood-stained bases may be seen, sometimes conspicuous in surrounding leukoplakia from previous attacks. Occasionally round or oval, they are more usually linear and follow either the summits or the folds of the lower closure pleats.

In more severe cases the whole or part of the tube is frankly haemorrhagic (Figs. 2-4) or has a dirty matt brown surface from soaking of unsloughed necrotic tissue with blood and bile pigments. Fragments of adherent dead mucosa show as soft brown ragged shreds, sometimes complete enough to form a zone between ulcerated oesophagus and viable epithelium (Fig. 5).

Altered blood may be so prominent that corrosive poisoning is suggested, excluded by the absence of mouth, throat, and stomach burns (Fig. 4). Blood clot is distributed either in streaks, in discrete patches, or as a smooth, black lining; it oozes from the raw surface layers and, collecting in the stomach and later vomited, is one cause of "causeless" coffee-ground haematemesis. The faecal occult blood is persistently positive and there may be severe iron-deficiency anaemia.

Often the whole tube is stripped of epithelium except for scraps at the two ends, and in parts not coated with blood the exposed tissues form a smooth or matt whitish membrane resembling atrophic epithelium.

In severe cases the distal oesophagus is swollen (the wall up to a centimetre thick suggesting hyper- 
FIGS. 2-4.-Severe acute digestion oesophagitis.

FIG. 2.-A, Cardia. B, Flecks of surviving squamous epithelium. C, Altered blood adherent to raw oesophagus.

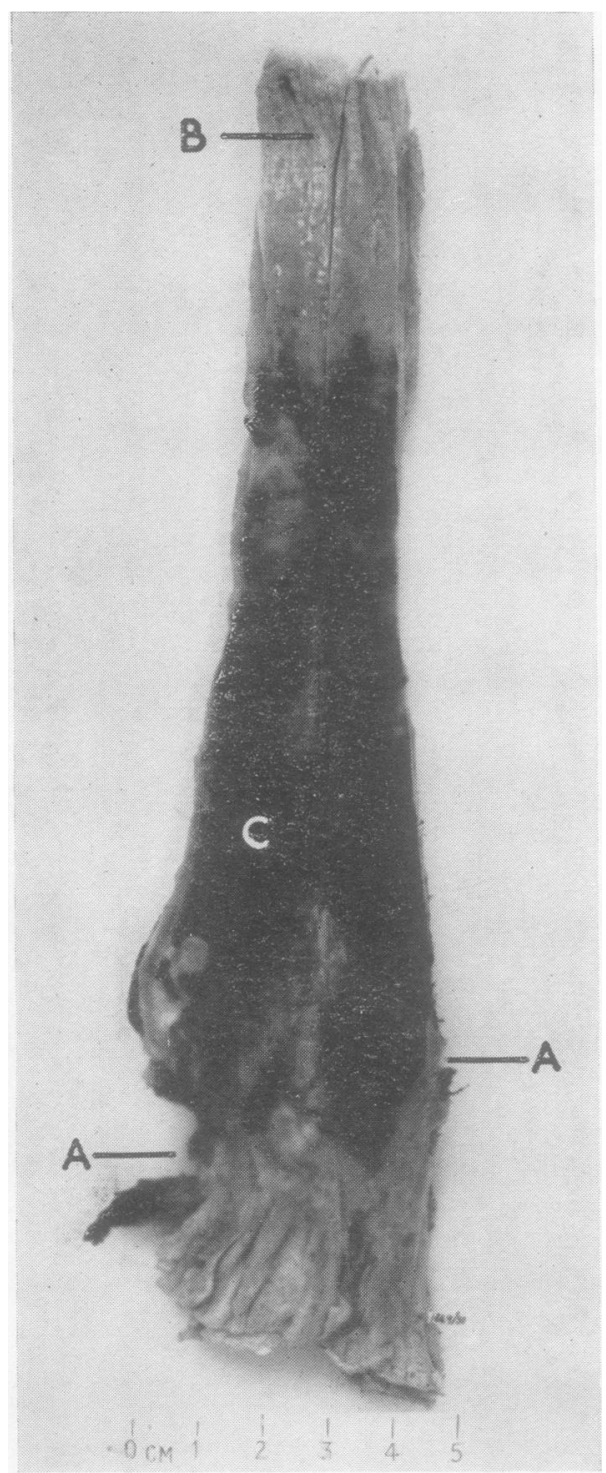

trophy), and patches of softened brown muscle may be exposed, sometimes with linear or tattered perforations; even short of perforation haemorrhagic, necrotic, and purulent posterior mediastinitis is likely to occur (Fig. 17). In extreme examples the lower part of the gullet becomes practically diffluent, disintegrating into a blackish pultaceous mass; infarction from secondary thrombosis may be an added factor in such cases.
Chronic.-As in the previous group the appearances are very variable; any length of $\frac{\bar{c}}{\overline{5}}$. the tube may be involved, but in the older cases $\frac{\sigma}{\sigma}$ the changes are more likely to be concentrated $\varrho$ at the lower end. In the more recent (active क chronic) there is dirty brown rough ulceration $\overrightarrow{0}$ in patches and streaks or involving the whole circumference, characteristically with islets of $\vec{\omega}$ surviving epithelium in or above the ulcerated $\underset{F}{+}$ area (Fig. 5). Extensive regeneration occurs from $\times$ the margins of these, sometimes appreciable to $\vec{O}$ the naked eye as a delicate hazy film covering $+\dot{\sim}$ adjacent raw surfaces. The islets vary in shape,

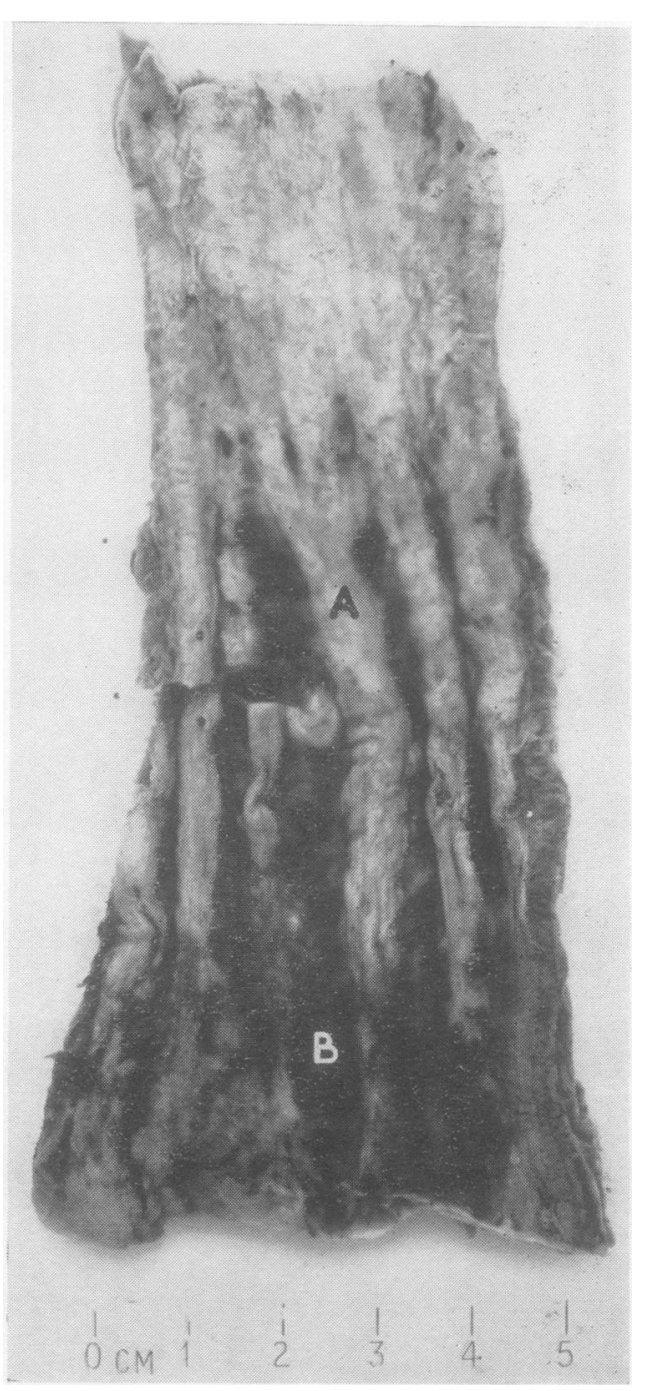

FiG. 3.-Whole lower oesophagus devoid of mucosa. A, Ridges of $\sigma$ acutely inflamed submucosa. B, Altered blood adherent to exposed muscle. 
size, and colour; the more recent are pinhead to lentil-sized, rounded, and grey-white ; bigger and older patches are flattened, scaly, white plaques like snakeskin (Figs. 6 and 7) or thick strips like candle grease gutterings (Fig. 8), separated by irregular channels of superficial ulceration. These changes may persist in or above the most chronic lesions or become part of an extensive leukoplakia (Fig. 11) which occasionally progresses to cancer. Active fibrosis begins at this stage and advances with time.

The most chronic lesions have two main anatomical forms, occasionally present together. In one, probably the less common, the most obvious "ulcers" in the usual sense are seen (Fig. 7).

In these: (a) The lower margin is usually fairly abrupt and is at the cardia, as concomitant oesophageal shortening prevents pinchcock sparing action; the proximal margin is long, flat and terraced (Diag. 2). (b) To casual inspection the

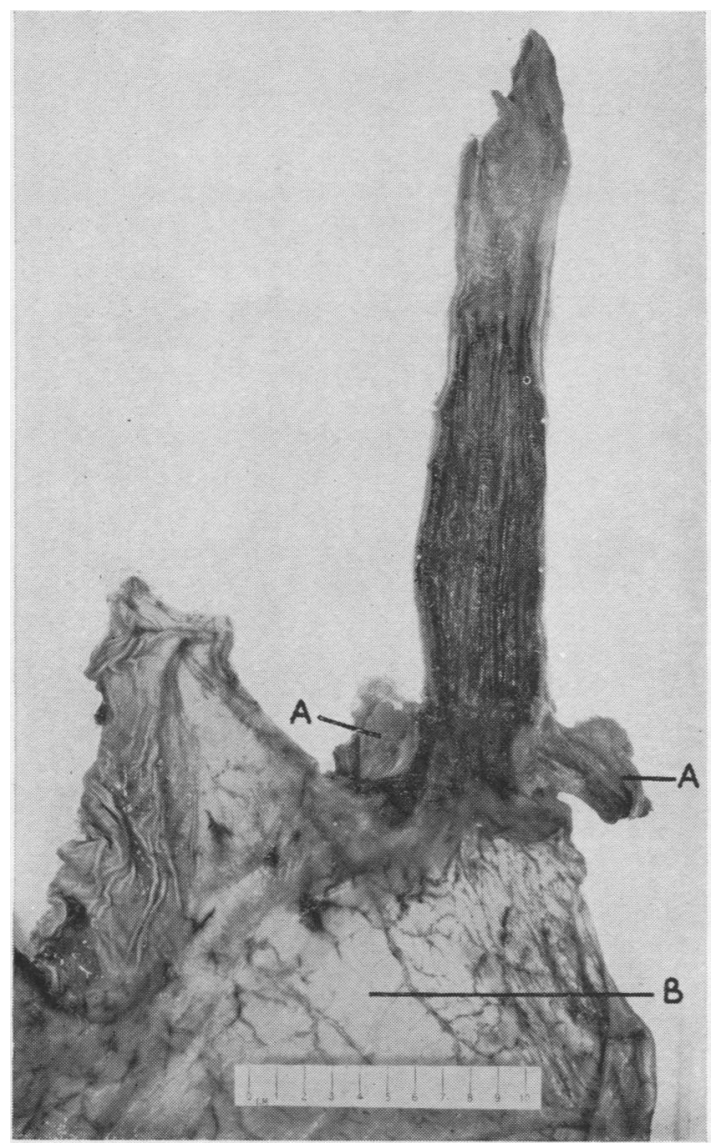

FIG. 4.-Whole oesophagus devoid of mucosa (the white specks are highlights). A, Diaphragm. B, Dilated stomach.
FIG. 5.-Acute on active chronic digestion oesophagitis. Necrotic epithelium (A) between surviving epithelium (B) and ulcerated zone (C). D, Islands of regenerating epithelium.

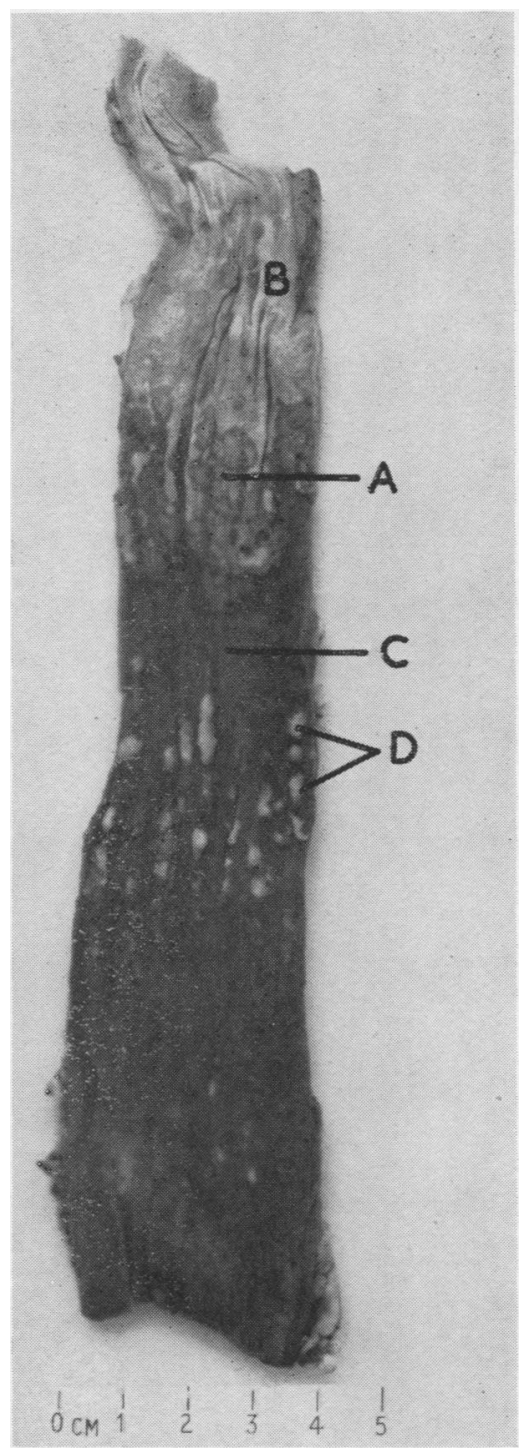

deepest penetration, being conspicuous, may be taken for the whole lesion; it may show brown muscle (Fig. 7) or dense white scar tissue.

In the second, probably more frequent form, the appearances are conditioned by great fibrosis (Figs. 9-14). This type has been described in detail, especially as occurring in children, by Belsey (1953). Although ulcerated, there is no excavation and the whole circumference for a variable length becomes smooth, white, and very thick-walled. Occasionally this reaches as high 


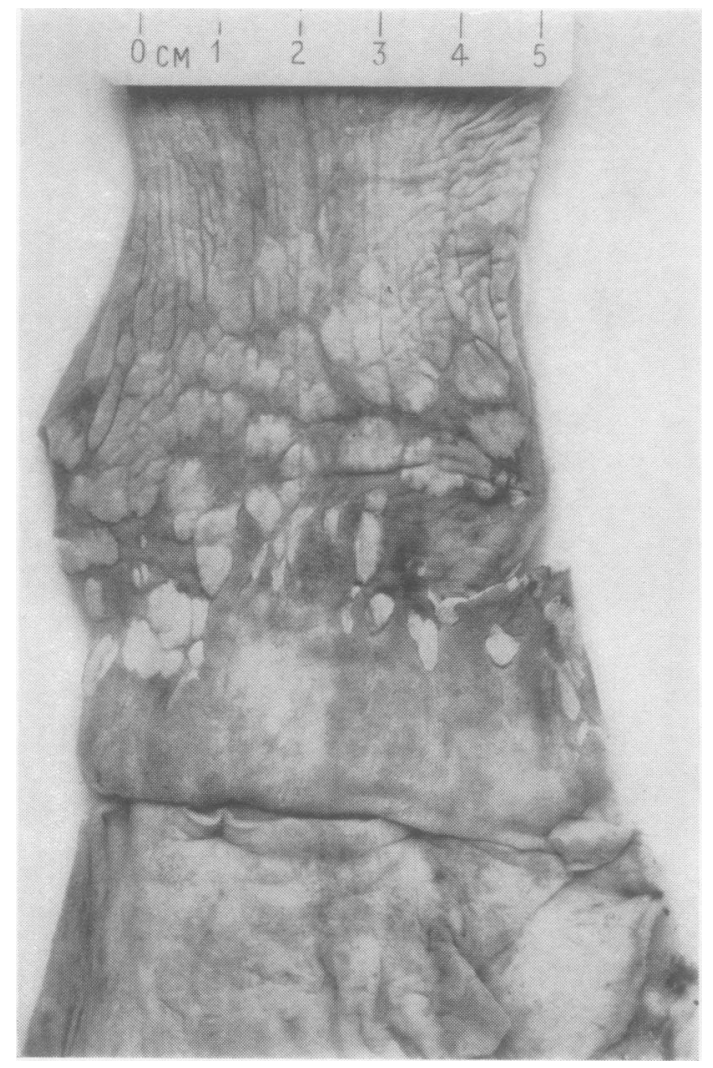

FIG. 6 FIGS. 6-14.-Chronic digestion oesophagitis. Figs. 9-14, predom-
inantly fibrous form with fixed hiatal hernia, required shorten-
ing, and stricture (A marks the subdiaphragmatic stomach).
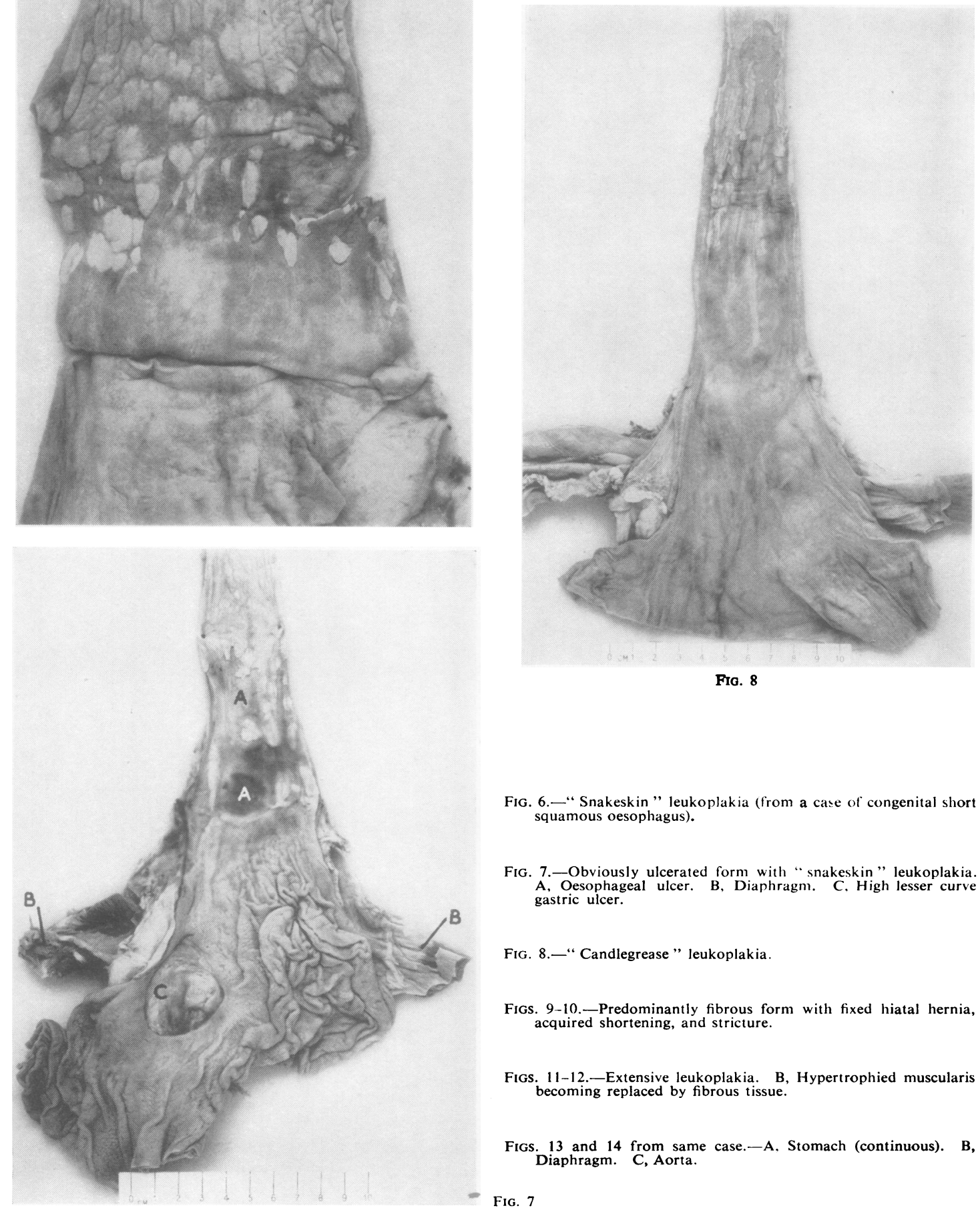

Fio. 8

Fig. 6.- "Snakeskin" leukoplakia (from a case of congenital short squamous oesophagus).

FIG. 7.-Obviously ulcerated form with "snakeskin" leukoplakia. A, Oesophageal ulcer. B, Diaphragm. C. High lesser curve gastric ulcer.

FIG. 8.- "Candlegrease" leukoplakia.

Figs. 9-10.-Predominantly fibrous form with fixed hiatal hernia, acquired shortening, and stricture.

Figs. 11-12.-Extensive leukoplakia. B, Hypertrophied muscularis becoming replaced by fibrous tissue.

FIGs. 13 and 14 from same case.-A. Stomach (continuous). B, Diaphragm. C, Aorta. 


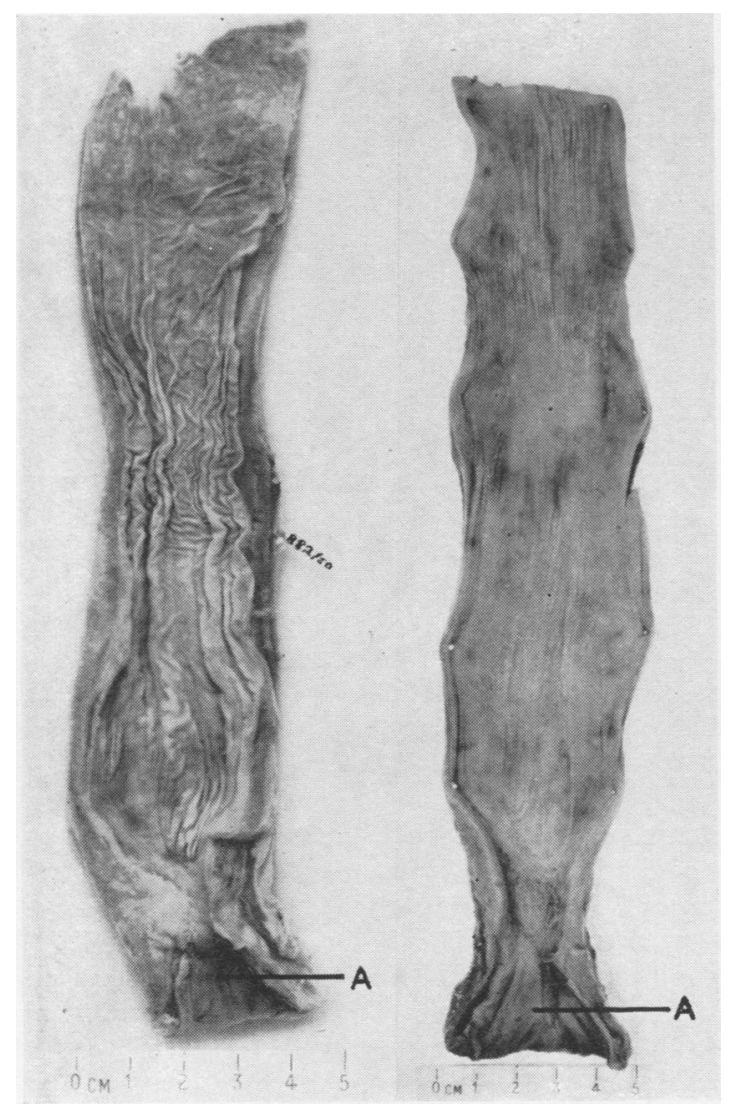

FIg. 9
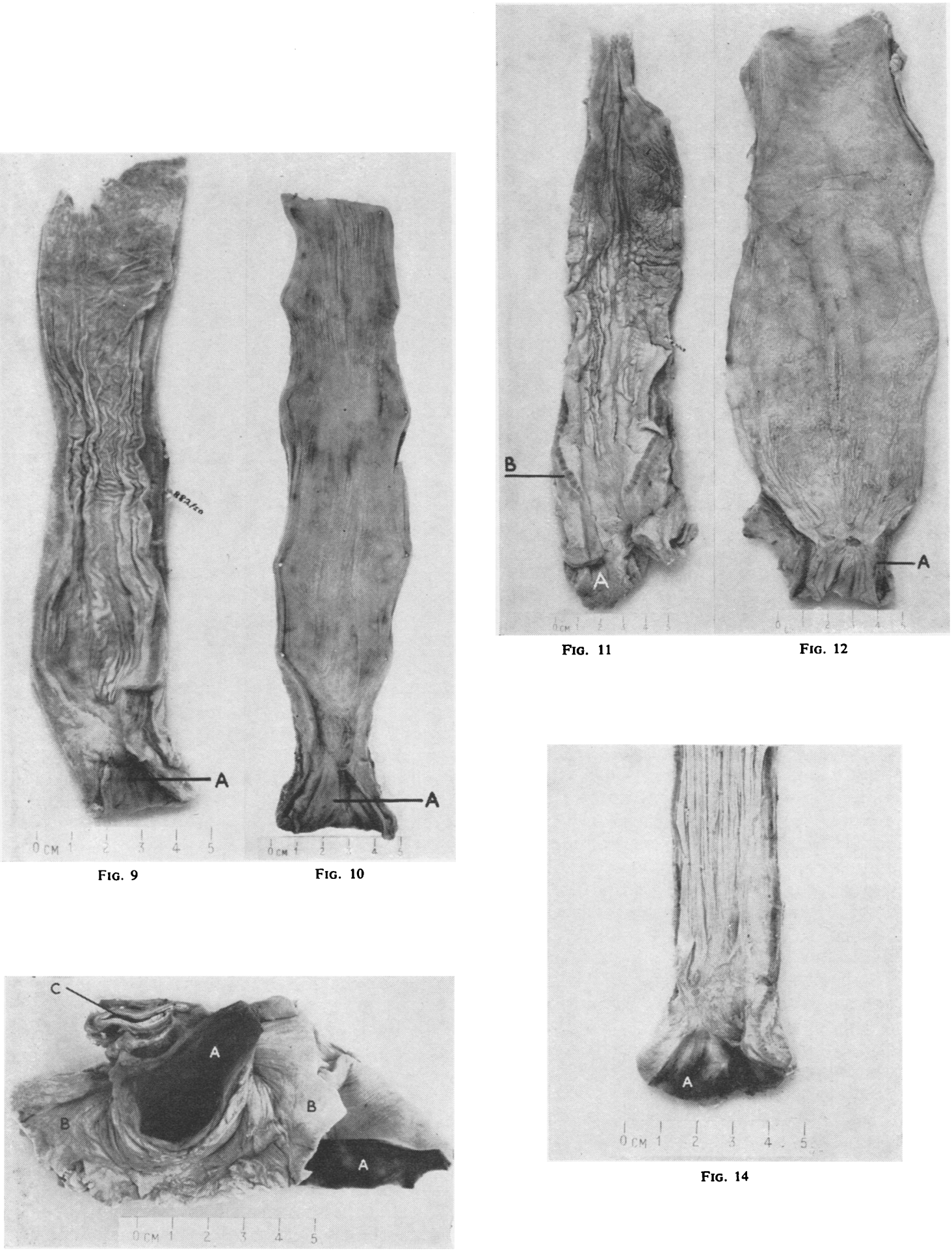

FIG. 11

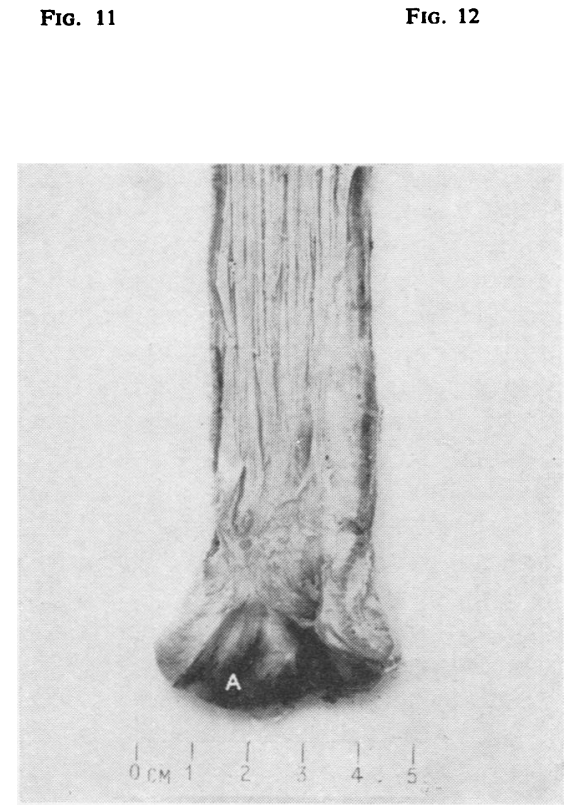

FIG. 14

Fig. 13

FIG. 12 


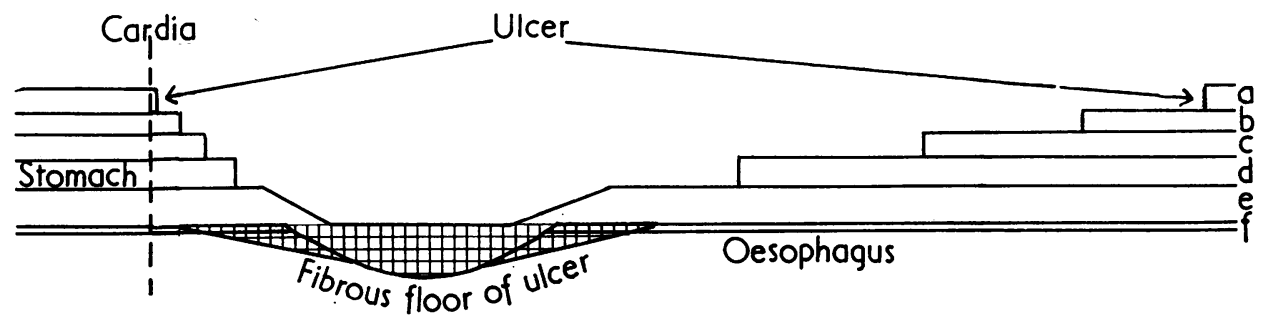

Diagram 2. $-\mathrm{a}=$ Squamous epithelium ; $\mathrm{b}=$ corium and muscularis mucosae ; $\mathrm{c}=$ submucosa ; $d=$ circular muscle ; $\mathrm{e}=$ longitudinal muscle ; $f=$ adventitia.

as the bifurcation of the trachea and the lower third of the gullet becomes a narrow, rigid tube like a peashooter. Usually, however, the main concentration is in the distal centimetre or two. As the scar tissue contracts two important secondary changes develop. Concentric contraction gives permanent stricture and in the case records the gradual conversion of intermittent spasm dysphagia to constant obstruction may be clear. Longitudinal contraction leads to permanent slight shortening which, following spasm shortening, makes the previously sliding hernia irreducible and ensures permanent incompetence of the pinchcock (see schema above). It is probably the commonest cause of permanent shortening of the gullet. The mediastinal gastric pouch $(2-3 \mathrm{~cm}$. long) shows as a soft, rather bulky cone lying between the scarred gullet above and the diaphragm below, its brown velvety mucosa thrown into a few vertical rugae.

A cut through the thick fibrous wall above the stricture may show recognizable remains of hypertrophied muscle "fossilized" in it (Fig. 11). Above the main damage, the epithelium is usually thickened in one of the ways mentioned above ; occasionally it may be thinned out by food stasis, with areas of secondary ulceration (Figs. 10 and 12), as in achalasia of the cardia and analogous to stercoral ulceration above a large gut obstruction.

Anatomically, strictured digestion oesophagitis differs from achalasia as follows: (a) Dilatation is far greater in achalasia. (b) There is no oesophageal shortening in achalasia (often the contrary). (c) Chronic ulcers and scarring are not seen in achalasia (Hurst and Stewart, 1929).

Differentiation from the sequelae of swallowed caustics is by the history, the absence of old scars in mouth and throat, and the presence of predisposing factors.

Microscopic Appearances.-These are also separated into acute and chronic.

Acute.-The changes vary with severity and duration but are generally those of acute non- specific ulcerative inflammation. Destroyed epithelium is mostly shed, but sometimes a little o remains, the junction with viable mucosa being very abrupt (Fig. 20). Raw corium is swollen, congested, and infiltrated by fibrin and leucocytes; or replaced by a haematoxyphil layer of $\mathbb{D}$

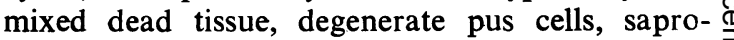
phytic organisms, and altered blood and bile pig- $\frac{O}{0}$ ments. The muscularis mucosae is resistant and may wholly limit a severe superficial inflamma- $\overrightarrow{0}$ tion. It is often greatly thickened, the strands of of muscle fibre separated by inflamed and swollen interstitial substances; the normal layer gives no hint of the amount of potentially space-occupying material that must exist between its bundles. Both corium and muscularis mucosae are often locally or widely destroyed.

In severe cases there is great swelling of the submucosa by oedema and fibrin exudation, becoming increasingly purulent with time. Fibrin occurs in patches and streaks or as an extensive network of strands and fibrils (Figs. 15 and 16) which merge with glassy collagen and lakes of degenerating red cells. Coexistent fibrin and $\dot{\circ}$ fibrinoid have been demonstrated in gastric ulcers 3 (Altshuler and Angevine, 1949). Slides of six of the present cases were stained with phosphotungstic acid-haematoxylin and the periodic-acid- $O$ Schiff reagent (as used by these writers); most if not all the deposited substance appeared to be fibrin and not fibrinoid. This was confirmed by the more reliable silver impregnation method of $N$ Gordon and Sweet (Glynn and Loewi, 1952).

The main muscle coats and adventitia are only N affected in severe cases. Short of necrosis and 0 perforation, there is fibrinous and leucocytic in- $c$ filtration of the swollen connective tissue between $\frac{C}{\Phi}$ degenerating muscle fibres, and the inflammation $\stackrel{\rho}{\rightarrow}$ rapidly becomes spreading and haemorrhagic if 0 the loose mediastinum is reached. Gross perforation is thus by no means necessary for acute $\stackrel{\square}{\Omega}$ mediastinitis, although if the mediastinitis appears $\mathbb{Q}$ disproportionately severe in a single section, perforation may have occurred elsewhere. 

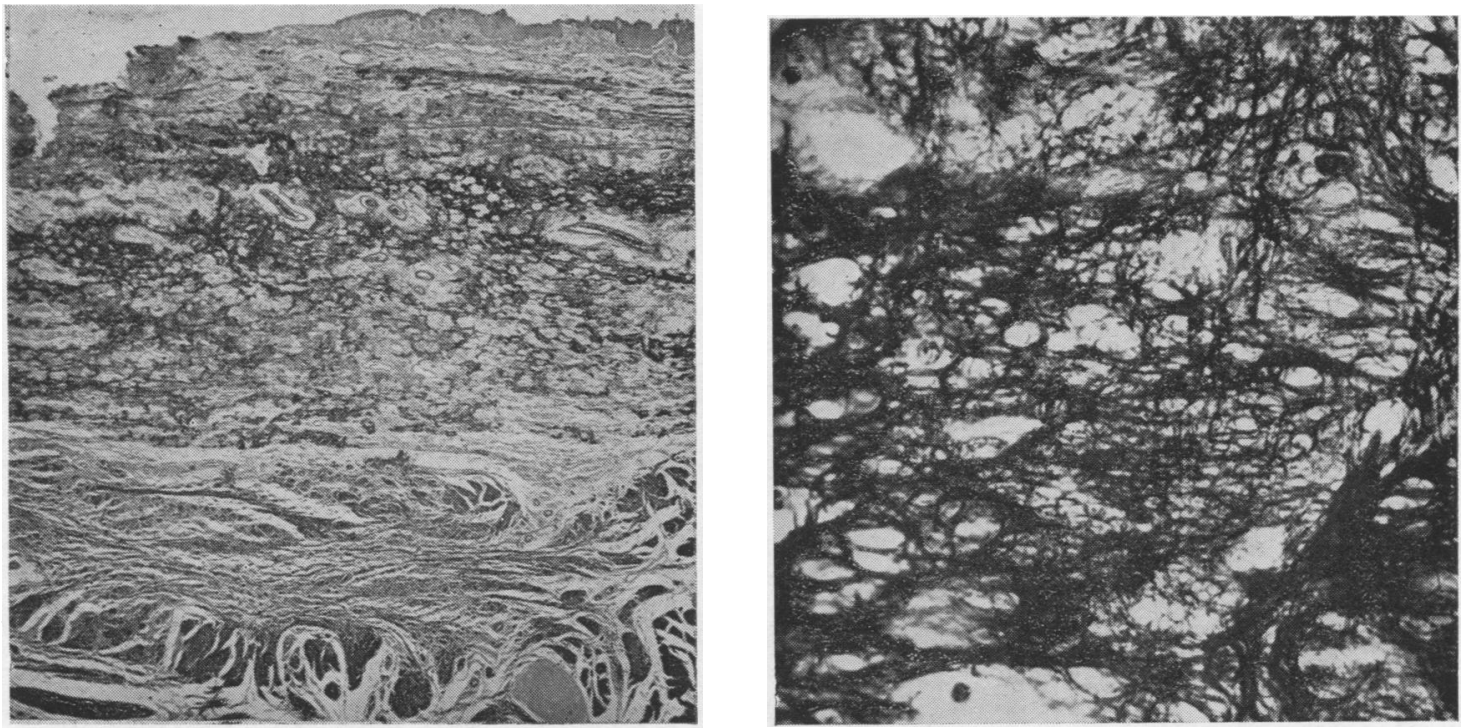

Figs. 15 and 16.-Fibrin in swollen submucosa. Fig. 15 stained with Mallory's phosphotungstic acid-haematoxylin for fibrin, $\times 11$. Fig. 16 shows detail of Fig. 15, $\times 322$.

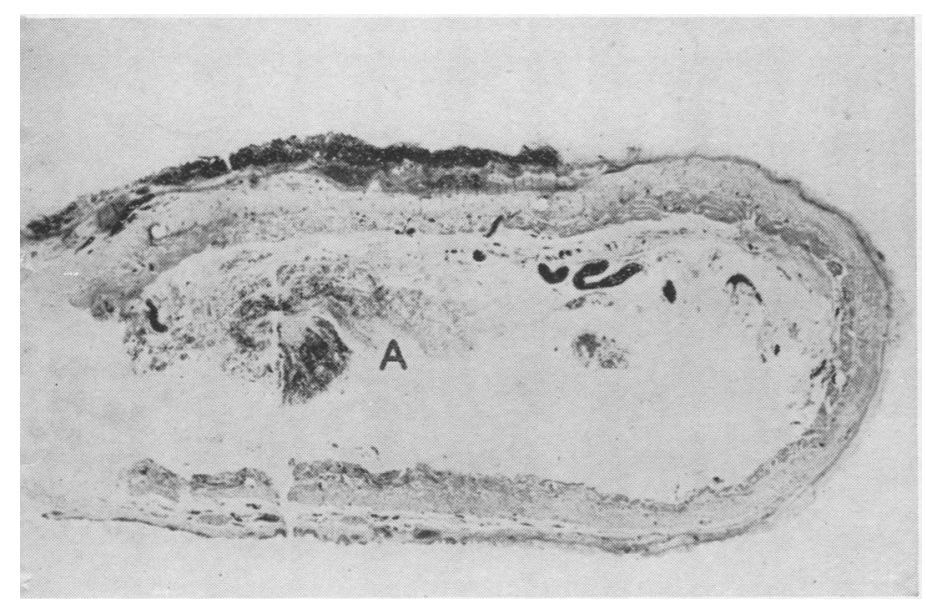

FIG. 17

FIGS. 15-20.-Acute changes.

FIGS. 17-19.-Superficial necrosis and haemorrhagico-purulent inflammation.

Fig. 17 is a long section stained with haematoxylin and eosin, $\times 1$ s. A indicates haemorrhagic mediastinitis.

Fig. 18 is stained with haematoxylin and eosin, $\times 6$. A, Necrotic mucosa and altered blood. B, Purulent zone. C, Muscularis. D, Mediastinum.

Fig. 19, also stained with haematoxylin and eosin $(\times 60)$, shows detail of the purulent zone.

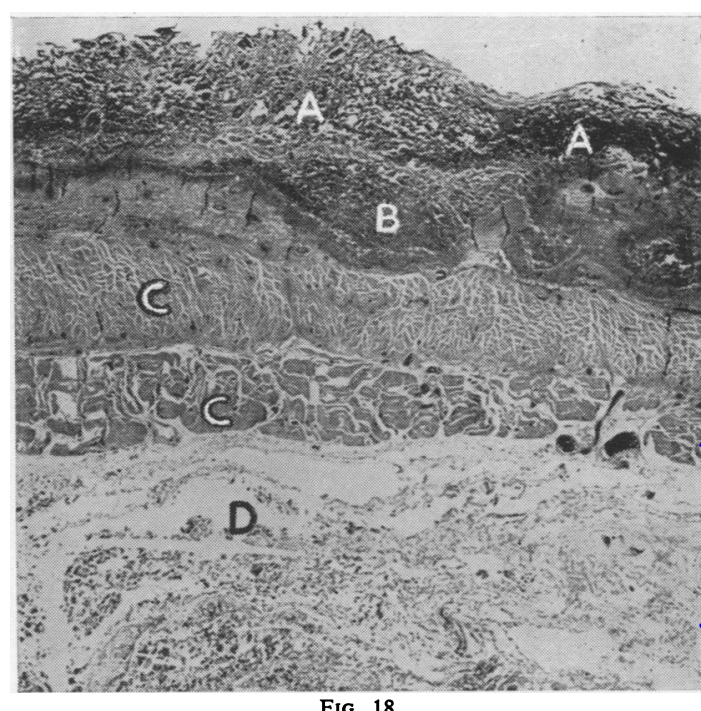

Fig. 18

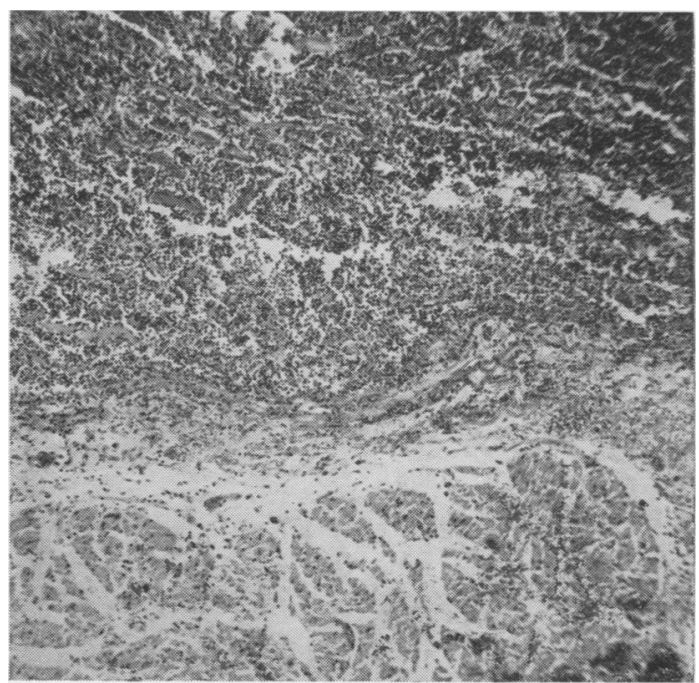

Fic. 19 
Subacute lesions differ from acute in that cellular infiltration is relatively more dense and lymphocytes, plasma cells, and histiocytes predominate. Congestion and oedematous swelling are less marked, but fibrin may persist and there is early fibroblastic proliferation. Necrotic surface tissues have usually been sloughed.

Chronic.-Continuation into the active chronic stage is mainly characterized by increasingly active fibrosis, with heavy round cell infiltration. The characteristic surviving epithelial plaques sometimes overlie much hypertrophied deep mucous glands (Fig. 21) and are possibly protected by a local concentration of mucus. The behaviour of these plaques, like the epithelium above the main ulcerated zone, is fairly constant. The centre of the islet, i.e., the part furthest from destruction, is thickened and occasionally cornified. The margins pass, sometimes abruptly, usually gradually, into a zone of thin regenerating squames which may cover an area of underlying granulation tissue many times the diameter of the central epithelial island (Fig. 21). The spreading edges may be only one or two cells thick and peter out over proliferating connective tissue cells (Fig. 22) ; a few of these young squames show mitosis (Fig. 23) and being very flat give the appearance of actively flowing out over the raw surface. Advance guards from contiguous islets eventually meet and coalesce and layers differentiate; basal cells become orientated at right angles and the upper layers stratify (Fig. 23). The appearances are as in healing skin ulcers generally and "pinch" grafts in particular; as with these the rate of healing is influenced by the degree of bacterial and fungal contamination.

Sometimes a single layer of short basal cells may survive between a frankly ulcerated area and unaffected mucosa: this "incomplete ulceration" is in contrast to the spreading regeneration described above. The layer sometimes shows buds of proliferation and differentiation, and clearly a complete epithelium may grow from it. Patterson (1935) recorded a case of complete healing about three weeks after a squamous cast of the gullet minus most of the basal layer had been ejected.

Inflammatory fibrosis of the wall may be severe and is chiefly in the submucosa, though paralleled to some extent in the intermuscular fascia.

In the flat terraced chronic ulcer described above the various coats are destroyed layer by layer, the steps abrupt in the distal margin but long proximally and fading off into fibrosis. The

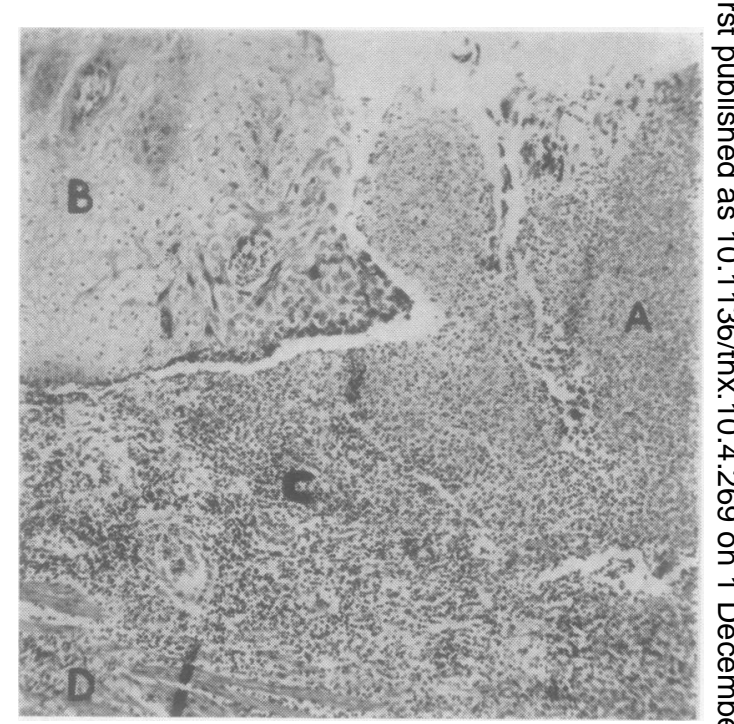

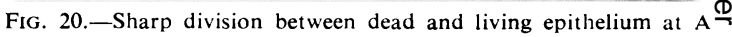
and $B$ respectively. Purulent inflammation of corium and muscularis mucosae at $\mathrm{C}$ and $\mathrm{D}$. Haematoxylin and eosin. 61

base may be formed by scar tissue and thickened adventitia only (Diag. 2).

In the excessively fibrous form there is replace-o ment of successive layers by indolent dense colla- $\frac{\alpha}{\alpha}$ genous tissue, sometimes over $1 \mathrm{~cm}$. thick ; and at the edges the gradual petering out of the propero layers may be seen to follow the familiar step pattern.

In neither of the two forms does the muscularis mucosae in the margin tend to fuse with the main muscle, as in chronic gastric ulcers (Newcomb. 1932): in both, the lower limit is very close to gastric mucosa and the epithelium above the main lesion is much thickened.

FIGS. 21-26.-Active chronic changes.

Fig. 21 shows epithelial regeneration when the whole surface is covered. Hypertrophied glands in thickened submucosa. Haematoxylin and eosin. 22.

Fig. 22 shows a layer of young squames, 1-2 cells thick, covering. granulation tissue. Haematoxylin and eosin, $\times 322 . \mathrm{N}$

Fig. 23.-Early stratification and mitosis (A) in regenerating squamous epithelium. Haematoxylin and eosin, $\times 450 . \sigma$

Fig. 24.-Absence of epithelium and inflammatory infiltration of corium and residual muscularis mucosae. Haematoxyling and eosin, 61 .

Fig. 25.-Regenerated epithelium. Severe inflammation of thickened corium and virtual destruction of the muscularis mucosae. Haematoxylin and eosin, $\times 61$.

Fig. 26.-Infiltration by lymphocytes, plasma cells, and histiocytes. Fibroblastic proliferation. Haematoxylin and eosin, $\times 322$. 


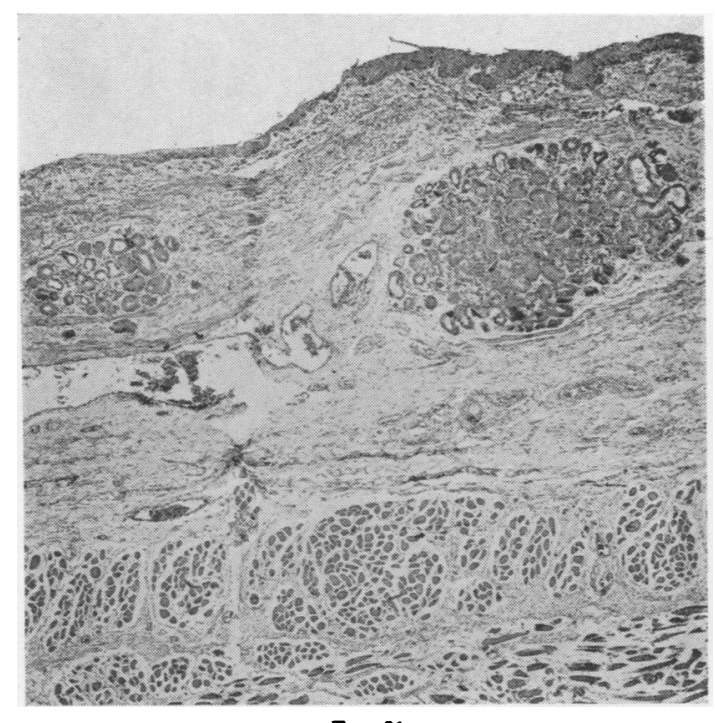

Fio. 21

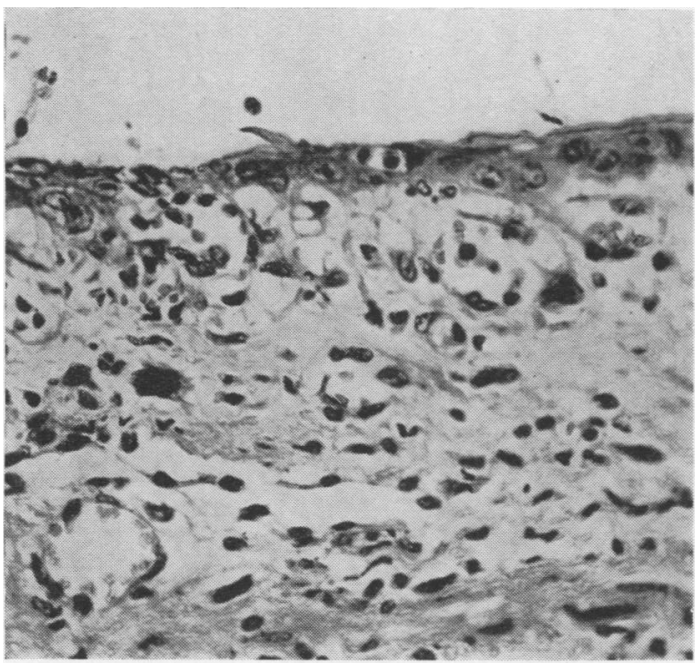

FIG. 22

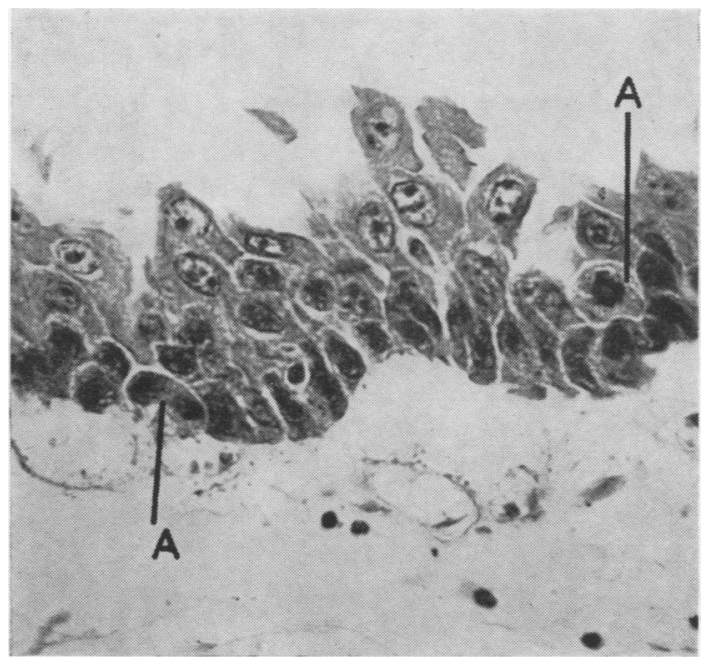

FIG. 23

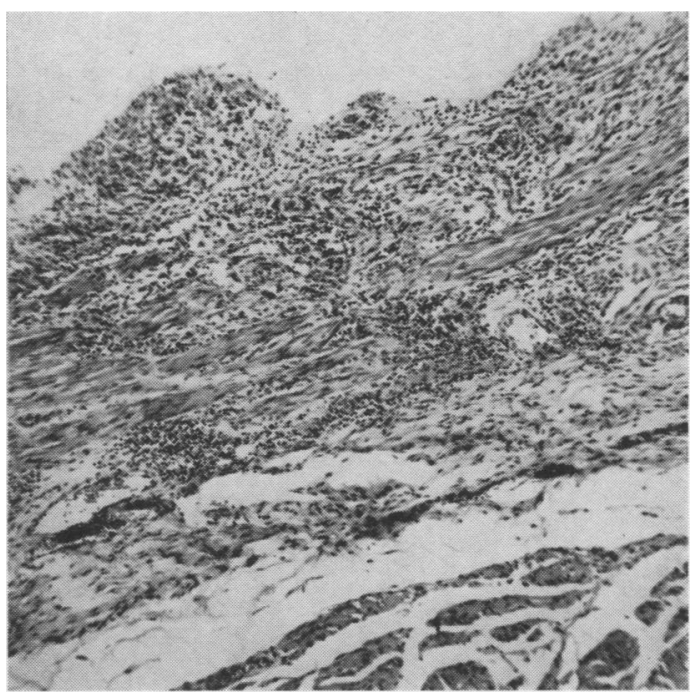

Fio. 24

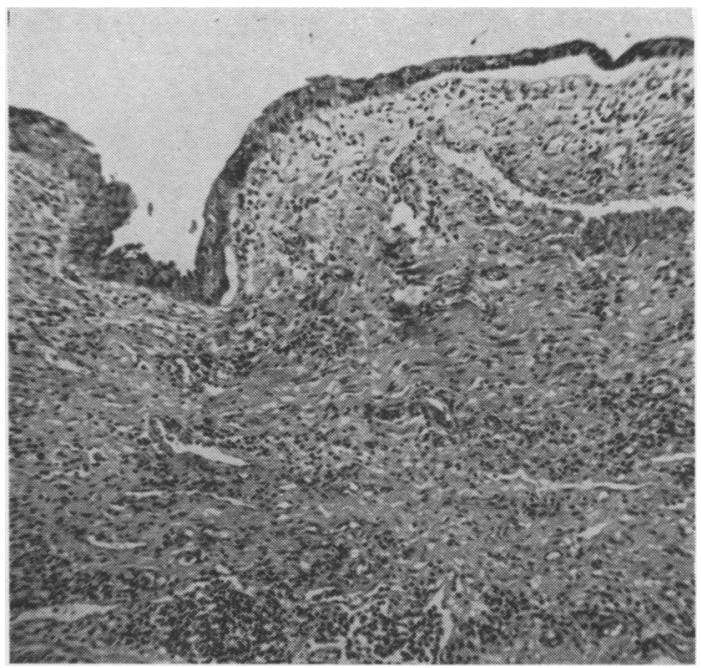

Pio. 25

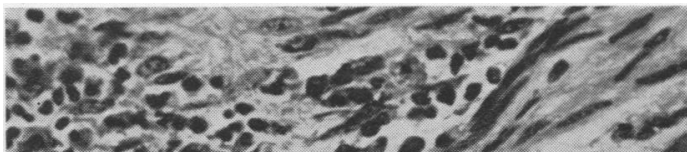
Fe 10 से

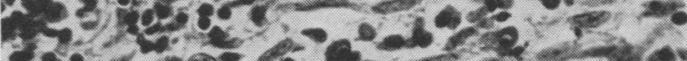

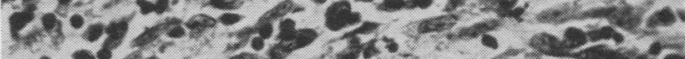

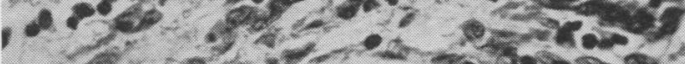

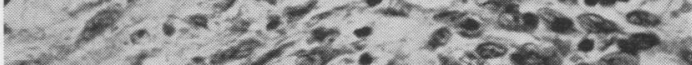

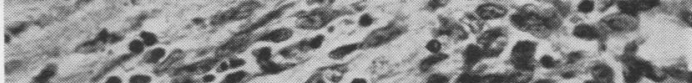
L

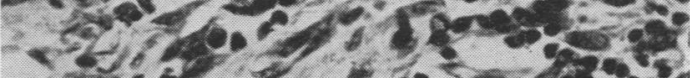

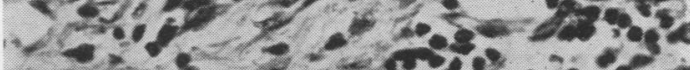

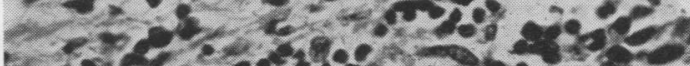

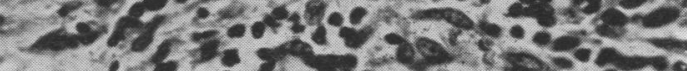

Fic. 26 
Fig. 27 a and b.-Chroni-

Chronic " terraced" ulcer of oesophagus from a case of congenital eniargement of hiatus. (a) $\times 1 \frac{1}{4}$ (approx.) and $(b) \times 4$. Both sections were stained with haematoxylin and van Gieson's stain and for elastic.

A, Squamous epithelium B. Muscularis mucosae. C, Fibrotic submucosa. D Circular muscle. E, Fibrotic longitudinal muscle in floor of ulcer. F, Gastric mucosa. G, Hypertrophied elastic ligament spanning large hiatus. H, Diaphragm.

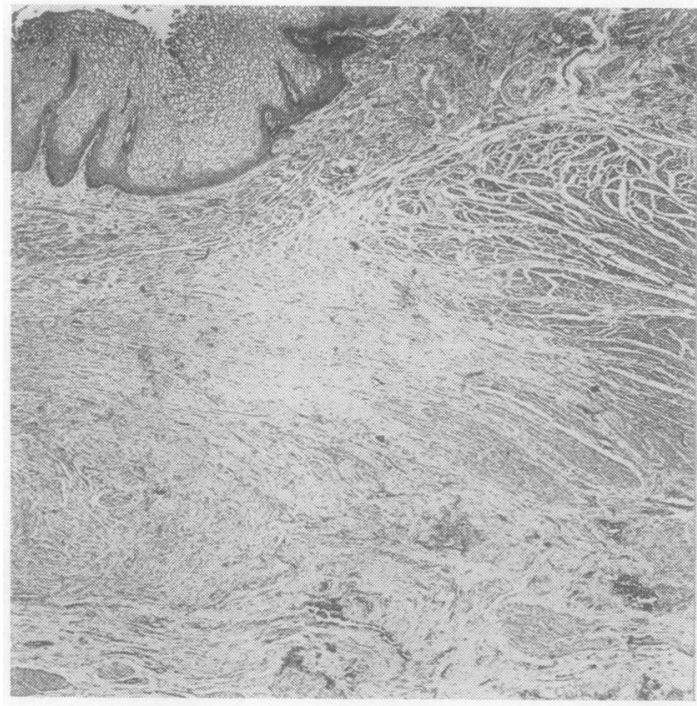

FIG. 28.-Leukoplakia. Severe fibrosis (cicatricial stricture). Same case as Fig. 12. Haematoxylin and eosin, $\times 22$. 


\section{CONCLUSIONS}

Peptic, reflux, or digestion oesophagitis may be defined as inflammation of the oesophagus directly due to digestion by gastric secretions; the rare intrathoracic gastric ulcer is now recognized as a separate condition, although the two lesions may coexist.

General recognition of the disease has been impeded by failure to integrate the various lesions as a pathological entity and by the use of many synonyms. Reflux oesophagitis and peptic oesophagitis are the terms most in use to-day. The former is open to the criticism that it describes an indirect and not the direct cause and that it does not include the theoretical possibility of digestion by the secretions of proximal ectopic gastric mucosa; also reflux suggests a passive state, not easily embracing persistent vomiting, a common predisposing condition. "Digestion oesophagitis," Quincke's original term slightly modified, seems both accurate and convenient.

Long held to be rare, the disease is now known to be common. In the present series (116 severe cases and 20,000 necropsies) the most representative incidence was $0.92 \%$ (acute $0.41 \%$; chronic $0.51 \%$ ). Slight lesions, without doubt much more common, were not included. All ages were included, from infants to octogenarians. Slight male preponderance was found $(1.3: 1)$, possibly connected with greater incidence of duodenal ulcer in men.

Indirect causes are those which allow enough gastric juice to be present in the oesophagus for digestion to occur. In this series they were arranged into extrinsic and intrinsic groups in relation to the cardiac closure mechanisms, and were found in $92.9 \%$ of cases; $66.3 \%$ were extrinsic and $39.8 \%$ were intrinsic (with fair comparability between acute and chronic). Thus in about two-thirds of cases the cardiac mechanisms had been overcome rather than had failed of themselves.

Extrinsic factors were $(a)$ persistent vomiting and nausea and $(b)$ increased intra-abdominal pressure, both sometimes present in the same case. Obviously, possible individual diseases in the first group are very numerous; but here, pyloric stenosis, dilatation of the stomach, paralytic ileus, and small bowel obstruction together accounted for about a third $(33.6 \%)$ of the total. Increased intra-abdominal pressure helps to squeeze stomach contents through the cardia, especially in certain postures, and may cause small pulsion hiatal herniae, particularly in old people.

Intrinsic factors were $(a)$ acquired hiatal hernia, (b) congenital enlargement of the hiatus and con- genital shortness of the squamous oesophagus, (c) mechanical interference with the crural tunnel, and $(d)$ organic lesions, e.g., ulcer or carcinoma, of the gastric cardia or high on the lesser curve (apparently not a common cause considering the frequency of these lesions). Primary abnormalities of the hiatus of the diaphragm associated with hiatal hernia are congenital enlargement, atrophy (often senile), and toxic laxity; the last two are probably common causes of oesophagitis, especially when influenced by posture (bending over or lying supine), but are difficult to assess in a pathological survey.

The interrelationship of vomiting and reflux, oesophageal shortening, oesophagitis, and hiatal hernia is complex. It seems that persistent vomiting and reflux can cause hiatal hernia (by spasm shortening), and hiatal hernia due to primary abnormalities of the diaphragm can cause vomiting and reflux. Both these sequences are associated with digestion oesophagitis. Once established, shortening may so disturb the closure mechanisms that a vicious circle is established and the condition may in the end become permanent by cicatricial fibrosis. Associated with shortening there may be spasm dysphagia (sometimes involving both ends of the tube; see also Abel, 1929), which may progress to permanent organic stricture of the lower end by scar tissue.

The pathology of the congenital short oesophagus, a comparative rarity, will be discussed elsewhere ; but it may be noted that, irrespective of ulcers in the gastric-lined part, chronic digestion of the short squamous part is the rule.

Gastric or duodenal ulcers were present in practically one-third of the series $(29.2 \%)$. Most, if not all, such cases have hyperchlorhydria at some stage (Hurst and Venables, 1939), and, as hyperacid juice digests living tissue much faster than normal juice, highly acid vomit or reflux is clearly more likely to cause oesophagitis.

Multiple predisposing factors were common $(42.5 \%)$. These may be either extrinsic or intrinsic, and the same lesion may act in more than one way as, for example, pyloric ulcer with severe vomiting and hyperchlorhydria.

The morbid anatomy is not summarized here ; the reader is referred to the text.

A few general points may be recapitulated. At any stage of the disease death may follow perforation into the mediastinum, pleura, pericardium or, if the leak is below the hiatal elastic ligament, into the upper abdomen. There is general liability to inhalation bronchopneumonia. A patient may become grossly anaemic from chronic or intermittent ooz- 
ing from raw surfaces $(\mathrm{Hb}$ values of $20 \%$ occurred in this series), the faecal occult blood being persistently positive; blood seeps into the stomach and, if vomited, is probably a common cause of apparently "causeless" coffee-ground haematemesis. Patients may have much pain and fear of eating or adopting certain postures; finally, perhaps long after the original cause, e.g., a long spell of vomiting, has ceased to operate, the resulting stricture may be treated and worsened by deep $x$ rays on a mistaken diagnosis of cancer. Some cases are labelled neurotic because their persistent complaint of indigestion is coupled with negative radiographs of stomach and duodenum or because variable dysphagia supervenes in a long "ulcer" history.

Prophylaxis by prevention of predisposing conditions, especially persistent vomiting, raised abdominal pressure, and excess acid, combined perhaps with local coating of the oesophagus by a protective film, e.g., olive oil, might prevent many cases altogether: or might reverse the changes before final scarring occurs, which surgery alone can cure.

Finally, perhaps one of the most interesting questions of this always secondary disease is why it does not invariably develop when it might be expected, as, for example, in some cases of pyloric stenosis.

\section{SUMMARY}

A short analysis of the literature relating to oesophagitis caused by digestion is given.

The aetiology, incidence, and morbid anatomy of 116 severe cases are discussed.

I wish to thank Drs. A. B. Bratton, M. Hynes, and S. H. G. Robinson for reading the draft and for many helpful suggestions. Mr. N. R. Barrett kindly permitted the inclusion of three cases previously published by him. I am indebted to Mr. G. W. Moore for the photographs

This paper is based on Part II of a thesis for the degree of D.M. of Oxford (1952).

\section{REFERENCES} Abel, A. L. (1929). Oesophageal Obstruction. Oxford University
Press, London.

Allison, P. R. (1946). J. thorac. Surg., 15, 308.

- (1948). Thorax, 3, 20.

- (1951). Surg. Gynec. Obstet., 92, 419

- (1953). Trans. med. Soc. Lond., 1951-2, 68, 15.
Allison, P. R., and Johnstone, A. S. (1953). Thorax, 8, 87. - and Royce, G. B. (1943). J. thorac. Surg., 12, 432 Altshuler, C. H., and Angevine, D. M. (1949). Amer. J. Path., 25, 1061 .

Anders, H. E., and Bahrmann, E. (1932). Z. klin. Med., 122, 736.

Arroyave, R., Clatworthy, H. W., and Wangensteen, O. H. (1950). Surgical Forum, Amer. Coll. Surgeons, p. 57. W. B. Saunders \& Co. (1951). Philadelphia.

Barrett, N. R. (1950). Brit. J. Surg., 38, 175.

- (1954). Ibid., 42. 231.

Bartels, E. C. (1935). Arch. Path., Chicago, 20, 369

Bartels, E. C. (1935). Arch. Path., Chicago, 20, 369.
Belsey, R. H. R. (1953). Trans. med. Soc. Lond., 1951-2, 68, 18.

Briggs, P. J., Dick, R. C. S., and Hurst, A. F. (1939). Proc. rov.

Soc. Med., 32, 1423 .

23, 391. (1936b). Ibid., 23, 550.

Carré, I. J., Astley, R., and Smellie, J. M. (1952). Lancet, 2, 1150.

Dick, R. C. S., and Hurst, A. F. (1942). Quart. J. Med., 11 105.

Dunhill, T. (1935). Brit. J. Surg., 22. 475.

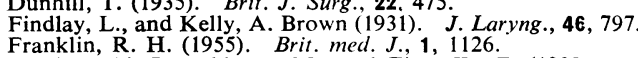

Friedenwald, J., Feldman, M., and Zinn, W. F. (1929). Amer. J. med. Sci., 177, 1 .

Garthshore, M. (1784). Medical Communications, 1, 242.

Gerlings, G. (1949). Bronchoscopie, p. 75.

Gerlings, G. (1949). Bronchoscopie, p. 75.

Glynn, L. E., and Loewi, G. (1952), J. Path.
Harman, J. B. (1952). Brit. med. J., 1, 941.

Harrington, S. W. (1940). Amer. J.SSurg., n.s., 50, 381

Hume, J. B. (1932). Brit. J. Surg., 19, 527.

Hurst, A. F. (1934). J. Amer. med. Ass., 102, 582. (1937). In Price. F. W., A Textbook of the Practice of Medicine, 5th ed., pp. 552-556. Oxford Univ. Press, London.

and Stewart, M. J. (1929). Gastric and Duodenal Ulcer. Oxford Univ. Press, London.

and Venables, J. F. (1939). Guy's Hosp. Rep., 89, 463.

Jackson, Chevalier (1929). J. Amer. med. Ass., 92, 369.

Johnstone, A. S. (1941). To Faculty of Radiologists, see Edit. Annotation, Lancet, 2, 18. (1943). Brit. J. Radiol 16, 357

Kaplan, S. B., and Zwaifler, N. (1942). Rev. Gastroent., 9, 108.

Kelly, A. Brown (1936). J. Laryng.. 51, 78.

Lawler, N. A., and McCreath, N. D. (1951). Lancet, 2, 369.

Lodge, K. V. (1955a). J. Path. Bact., 69, 17.

(1955b). Thorax, 10, 56.

Lyall, A. (1935). Brit. med. J., 2, 578

(1937). Brit. J. Surg., 24, 534.

Maingot, R. (1944). Postgrad. med. J., 20, 278.

Newcomb, W. D. (1932). Brit. J. Surg., 20, 279.

Patterson, T. C. (1935). J. Path. Bact., 40, 559.

Peters, P. M. (1952). Thesis, Oxford University.

Peters, P. M. (1952). Thesis,
- (1955). Thorax, 10, 27.

Polson, C. (1936). J. Path. Bact., 42, 317.

Price, P. B., and Lee, T. F. (1946). Surg. Gynec. Obstet., 83, 61 - (1947). Ibid., 84, 959

Pringle. J. H., and Teacher, J. H. (1919). Brit. J. Surg., 6, 523. -Stewart, L. T., and Teacher, J. H. (1921). J. Path. Bact., 24, 396.

Quincke, H. (1879). Dtsch. Arch. klin. Med., 24, 72. Quincke, H. (1879). Dtsch. Arch. klin. Med., 24, 72.
Rector, L. E., and Connerley, M. L. (1941). Arch. Path., Chicago,
31, 285.

Rennie, J. B., Land, F. T., and Park, S. D. Scott (1949). Brit. med. J., 2,1443 .

Ripley, H. R., Leary, W. V., Grindlay, J. H., Seybold, W. D., and Code, C. F. (1950). Surgical Forum, Amet. Coll. Surgeons, p. 60 . W. B. Saunders \& Co. 1951). Philadelphia.

Schatzki, R. (1932). Fortschr. Röntgenstr., 45, 177.

Selye, H. (1938). Canad. med. Ass. J., 39, 447.

Simmons, S. F. (1784). Medical Communications, 1, 228.

Smithers, D. W. (1945). Brit. J. Radiol., 18, 199.

Stewart, M. J., and Hartfall, S. J. (1929). J. Path. Bact., 32, 9

Taylor, A. L. (1927). Ibid., 30, 415.

Terracol, J. (1938). Les Maladies de l'Oesophage. Masson, Paris $N$

Tileston, W. (1906). Amer. J. med. Sci., 132, 240.

Wells, C., and Johnston, J. H. (1955). Lancet, 1, 937.

Wright, G. Payling (1950). An Introduction to Pathology, 1st ed., pp. 9, 10. Longmans, Green, London. 